NASA/TM-2015-218867

\title{
In-Situ Resource Utilization for Space Exploration: Resource Processing, Mission-Enabling Technologies, and Lessons for Sustainability on Earth and Beyond
}

A.F. Hepp, B.A. Palaszewski, G.A. Landis, and D.A. Jaworske

Glenn Research Center, Cleveland, Ohio

A.J. Colozza

Vantage Partners, LLC, Brook Park, Ohio 44142

M.J. Kulis

Glenn Research Center, Cleveland, Ohio

R.S. Heller

Sandia National Laboratories, Albuquerque, New Mexico 


\section{NASA STI Program . . . in Profile}

Since its founding, NASA has been dedicated to the advancement of aeronautics and space science. The NASA Scientific and Technical Information (STI) Program plays a key part in helping NASA maintain this important role.

The NASA STI Program operates under the auspices of the Agency Chief Information Officer. It collects, organizes, provides for archiving, and disseminates NASA's STI. The NASA STI Program provides access to the NASA Technical Report Server-Registered (NTRS Reg) and NASA Technical Report ServerPublic (NTRS) thus providing one of the largest collections of aeronautical and space science STI in the world. Results are published in both non-NASA channels and by NASA in the NASA STI Report Series, which includes the following report types:

- TECHNICAL PUBLICATION. Reports of completed research or a major significant phase of research that present the results of NASA programs and include extensive data or theoretical analysis. Includes compilations of significant scientific and technical data and information deemed to be of continuing reference value. NASA counter-part of peer-reviewed formal professional papers, but has less stringent limitations on manuscript length and extent of graphic presentations.

- TECHNICAL MEMORANDUM. Scientific and technical findings that are preliminary or of specialized interest, e.g., "quick-release" reports, working papers, and bibliographies that contain minimal annotation. Does not contain extensive analysis.
- CONTRACTOR REPORT. Scientific and technical findings by NASA-sponsored contractors and grantees.

- CONFERENCE PUBLICATION. Collected papers from scientific and technical conferences, symposia, seminars, or other meetings sponsored or co-sponsored by NASA.

- SPECIAL PUBLICATION. Scientific, technical, or historical information from NASA programs, projects, and missions, often concerned with subjects having substantial public interest.

- TECHNICAL TRANSLATION. Englishlanguage translations of foreign scientific and technical material pertinent to NASA's mission.

For more information about the NASA STI program, see the following:

- Access the NASA STI program home page at http://www.sti.nasa.gov

- E-mail your question to help@sti.nasa.gov

- Fax your question to the NASA STI Information Desk at 757-864-6500

- Telephone the NASA STI Information Desk at 757-864-9658

- Write to:

NASA STI Program

Mail Stop 148

NASA Langley Research Center Hampton, VA 23681-2199 
NASA/TM-2015-218867

\section{In-Situ Resource Utilization for Space Exploration: Resource Processing, Mission-Enabling Technologies, and Lessons for Sustainability on Earth and Beyond}

A.F. Hepp, B.A. Palaszewski, G.A. Landis, and D.A. Jaworske

Glenn Research Center, Cleveland, Ohio

A.J. Colozza

Vantage Partners, LLC, Brook Park, Ohio 44142

M.J. Kulis

Glenn Research Center, Cleveland, Ohio

R.S. Heller

Sandia National Laboratories, Albuquerque, New Mexico

Prepared for

Propulsion and Energy Forum 2014

sponsored by the American Institute of Aeronautics and Astronautics

Cleveland, Ohio, July 28-30, 2014

National Aeronautics and

Space Administration

Glenn Research Center

Cleveland, Ohio 44135 


\section{Acknowledgments}

The following students are acknowledged for their contributions to this work during summer fellowships at NASA Glenn Research Center (GRC): Pierce Gordon, Karen Guerrero-Medina, Blain McLeod, Thomaz Santana, and Innocent Udom. We also acknowledge technical discussions with, and valuable input from our GRC colleagues, Ms. Diane Linne, Mr. Michael Piszczor, and Dr. Kurt Sacksteder, and from our numerous co-authors from previous publications.

This report contains preliminary findings, subject to revision as analysis proceeds.

Trade names and trademarks are used in this report for identification only. Their usage does not constitute an official endorsement, either expressed or implied, by the National Aeronautics and Space Administration.

Level of Review: This material has been technically reviewed by technical management.

Available from

NASA STI Program

Mail Stop 148

NASA Langley Research Center

Hampton, VA 23681-2199
National Technical Information Service 5285 Port Royal Road Springfield, VA 22161

703-605-6000

This report is available in electronic form at http://www.sti.nasa.gov/ and http://ntrs.nasa.gov/ 


\title{
In-Situ Resource Utilization for Space Exploration: Resource Processing, Mission-Enabling Technologies, and Lessons for Sustainability on Earth and Beyond
}

\author{
A.F. Hepp, B.A. Palaszewski, G.A. Landis, and D.A. Jaworske \\ National Aeronautics and Space Administration \\ Glenn Research Center \\ Cleveland, Ohio 44135 \\ A.J. Colozza \\ Vantage Partners, LLC \\ Brook Park, Ohio 44142 \\ M.J. Kulis \\ National Aeronautics and Space Administration \\ Glenn Research Center \\ Cleveland, Ohio 44135 \\ R.S. Heller \\ Sandia National Laboratories \\ Albuquerque, New Mexico 87123
}

\begin{abstract}
As humanity begins to reach out into the solar system, it has become apparent that supporting a human or robotic presence in transit and/or on station requires significant expendable resources including consumables (to support people), fuel, and convenient reliable power. Transporting all necessary expendables is inefficient, inconvenient, costly, and, in the final analysis, a complicating factor for mission planners and a significant source of potential failure modes. Over the past 25 years, beginning with the Space Exploration Initiative, researchers at the NASA Glenn Research Center (GRC), academic collaborators, and industrial partners have analyzed, researched, and developed successful solutions for the challenges posed by surviving and even thriving in the resource limited environment(s) presented by near-Earth space and nonterrestrial surface operations. In this retrospective paper, we highlight the efforts of the co-authors in resource simulation and utilization, materials processing and consumable(s) production, power systems and analysis, fuel storage and handling, propulsion systems, and mission operations. As we move forward in our quest to explore space using a resource-optimized approach, it is worthwhile to consider lessons learned relative to efficient utilization of the (comparatively) abundant natural resources and improving the sustainability (and environment) for life on Earth. We reconsider Lunar (and briefly Martian) resource utilization for potential colonization, and discuss next steps moving away from Earth.
\end{abstract}

\section{Nomenclature}

$\mathrm{C} 1$ generic term for simple one-carbon $\left(\mathrm{CO}, \mathrm{CO}_{2}, \mathrm{CH}_{4}\right)$ compounds

$\mathrm{CH}_{4} \quad$ chemical symbol for methane

$\mathrm{CO} \quad$ chemical symbol for carbon monoxide

$\mathrm{CO}_{2} \quad$ chemical symbol for carbon dioxide

CRRM carbothermal regolith reduction module

ECLSS Environmental Control and Life Support System

$\Delta \mathrm{G} \quad$ Gibbs free energy change

$\Delta \mathrm{H}$ enthalpy change, related to Gibbs free energy change: $\Delta \mathrm{G}=\Delta \mathrm{H}-\mathrm{T} \Delta \mathrm{S}$

${ }^{3,4} \mathrm{He} \quad$ helium-3 or -4 , an isotope of He determined by total of protons + neutrons

F-T(S) Fischer-Tröpsch (synthesis)

$\mathrm{H}_{2} \quad$ chemical symbol for molecular hydrogen

$\mathrm{H}_{2} \mathrm{O} \quad$ chemical symbol for water

$\mathrm{I}_{\mathrm{sp}} \quad$ Specific impulse, a measure of effectiveness of a fuel

ISRU in situ resource utilization

ISS International Space Station

LEO low Earth orbit

LRR Logistics Reduction and Repurposing

$\mathrm{N}_{2} \quad$ chemical symbol for molecular nitrogen

NTP nuclear thermal propulsion

$\mathrm{O}_{2} \quad$ chemical symbol for molecular oxygen

PAG plasma assisted gasification

$\mathrm{Re} \quad$ Reynolds number of a fluid flow, related to amount of turbulence 
Sabatier exothermic reaction that reduces $\mathrm{CO}_{2}$ with molecular $\mathrm{H}_{2}$ to $\mathrm{CH}_{4}$ and $\mathrm{H}_{2} \mathrm{O}$

SBIR Small Business Innovative Research Program

syn-gas synthesis gas: $\mathrm{H}_{2} / \mathrm{CO}$ gaseous mixture, typical ratio is $2-3: 1$

$\Delta \mathrm{V} \quad$ Delta- $\mathrm{V}$ is related to the relative velocity needed to change trajectories

WTE waste-to-energy technologies

\subsection{Introduction and Background}

As NASA moves forward with plans to support human exploration of the solar system, a critical need arises to supply basic materials such as oxygen $\left(\mathrm{O}_{2}\right)$ and water $\left(\mathrm{H}_{2} \mathrm{O}\right)$, food, propellants, and other materials (radiation shielding, clothing, etc.) (Ref. 1). Thus far, exploration has relied on materials brought from Earth; this conservative approach, while quite costly, minimizes risk to crews. As mankind ventures farther from Earth and for greater periods of time, it becomes imperative to develop technologies and mission architectures that utilize local resources such as lunar regolith or Martian atmosphere, referred to as in-situ resource utilization or ISRU (Ref. 2).

Therefore, ISRU is an overall approach for human exploration based upon utilization of scarce resources (and anthropogenic material(s)) derived from extraterrestrial bodies (surface and extant atmosphere) including planets, moons, and asteroids. GRC has a 25 year legacy in developing technologies to contribute to this technically challenging exploration approach. The work pioneered and supported by GRC includes concept proposals, mission studies, hardware (including contractorprovided hardware) development, and technology demonstrations to produce propellants (and other expendables) using extraterrestrial resources for the exploration of the Moon (Refs. 3 to 5), Mars (Refs. 6 to 8), and beyond (Refs. 9 and 10).

For sustainability considerations on Earth, efficient utilization of raw materials and energy often involves recycling: re-use or recovery of hydrocarbons (or syn-gas, vide infra) from waste plastics (Ref. 11); another critical concern is production of clean water from salt or wastewater. These can be related back to long-term in-flight or surface-operating utilization of waste and trash to produce essential materials such as $\mathrm{H}_{2} \mathrm{O}$, propellants, and $\mathrm{O}_{2}$ (Ref. 12). On a rocky surface, lighter elements such as $\mathrm{O}_{2}$, nitrogen $\left(\mathrm{N}_{2}\right)$, and particularly carbon and hydrogen $\left(\mathrm{H}_{2}\right)$ are either not readily available or strongly bonded to metal or metalloid atoms in loose regolith and rocks (especially $\mathrm{O}_{2}$ ) requiring significant energy for extraction (Refs. 3 to 5).

For a variety of economic, logistical, and technical reasons, transportation fuels production (including aerospace propellants) from non-traditional sources (gases, waste materials, and biomass) has been pursued for decades. These reasons include reducing terrestrial waste streams simultaneous with energy conversion, plentiful biomass, new low-cost methane $\left(\mathrm{CH}_{4}\right)$ sources made available by aggressive new extraction methods, and/or ISRU of limited resources found in space (or extraterrestrial surface); they each present significant technological and business opportunities being realized by a new generation of visionary entrepreneurs (Ref. 13).

From an operational perspective of ISRU, we have explored processing of available resources (Refs. 3 and 7), use of solar concentrator technologies to process raw materials (Refs. 4 and 5 ), and compared methods of production for green aerospace fuels processing (Ref. 13) including a preliminary comparison of methods using a two-stage production approach (Ref. 12). In this report, we provide a brief retrospective while looking towards the future. The ISRU rationale and paradigm are described; fundamental considerations and mission-enabling technologies are highlighted. Finally, we will discuss a series of issues to be addressed while developing technologies relevant to sustaining life on the Earth, Moon, and beyond.

\subsection{Processing Technologies: Terrestrial Beginnings and ISRU Applications}

The concept of "living off the land" imposes severe constraints for utilization of power, propellants, and expendables. The normal rigors (mass, space limitations and environmental challenges) imposed by space travel are magnified by a resource-limited situation. On the other hand, enhanced energy efficiency and minimal launch mass will simplify missions (and increase successful outcomes) by resultant limitations to planned activities. Thus the technical hurdles and challenges alluded to above will stimulate development of technology solutions for space exploration that can be spun off to solve terrestrial problems for defense, dual-use, and commercial transportation, power generation, and efficient resource utilization (Ref. 14). This section introduces new technologies and/or applications for materials processing, hardware engineering, and systems integration to enable solutions for the challenging technical hurdles of space exploration and green energy conversion.

\subsection{Fuel Production From Alternative Feedstocks: Thermodynamics and Reactors}

An important consideration for fuel production from non-petroleum raw materials begins with the energy balance of the chemical reactions at the heart of the various unit operations that comprise the processing steps and related hardware. The enthalpy $(\Delta \mathrm{H})$ change is an indication of whether a transformation releases energy (exothermic, negative $\Delta H$ ) or requires energy input (endothermic, positive $\Delta \mathrm{H}$ ). Depending upon the feedstock and/or desired products, combining endothermic and 
exothermic reactions minimizes the energy that must be added to the overall system. Several endothermic reactions are available to produce syn-gas (carbon monoxide $(\mathrm{CO})$ and $\mathrm{H}_{2}$ ) (Ref. 15) or producer gas (includes other gases such as $\mathrm{H}_{2} \mathrm{O}, \mathrm{O}_{2}$, $\mathrm{CH}_{4}$ and carbon dioxide $\left(\mathrm{CO}_{2}\right)$ ) (Ref. 16) from steam reforming of coal (1) or biomass (2), or $\mathrm{CO}_{2}$ reforming of $\mathrm{CH}_{4}$ (3), for example.

$$
\begin{gathered}
\mathrm{C}+\mathrm{H}_{2} \mathrm{O} \leftrightarrows \mathrm{CO}+\mathrm{H}_{2} \quad \Delta \mathrm{H}=+31 \mathrm{kcal} / \mathrm{mol} \\
\mathrm{C}_{6} \mathrm{H}_{12} \mathrm{O}_{6}+6 \mathrm{H}_{2} \mathrm{O} \leftrightarrows 6 \mathrm{CO}_{2}+12 \mathrm{H}_{2} \quad \Delta \mathrm{H}=+145 \mathrm{kcal} / \mathrm{mol} \\
2 \mathrm{CH}_{4}+\mathrm{CO}_{2} \leftrightarrows 2 \mathrm{CO}+4 \mathrm{H}_{2} \quad \Delta \mathrm{H}=+59 \mathrm{kcal} / \mathrm{mol}
\end{gathered}
$$

This step can be followed by an exothermic reaction to break $\mathrm{C}-\mathrm{O}$ and $\mathrm{H}-\mathrm{H}$ bonds, making $\mathrm{C}-\mathrm{C}$ bonds and $\mathrm{C}-\mathrm{H}$ bonds such as the Sabatier (Eq. (4)) (Ref. 17), methanation (5) (Ref. 18) or thermodynamically equivalent Fischer-Tröpsch (6) (Ref. 19) reactions.

$$
\begin{gathered}
\mathrm{CO}_{2}+4 \mathrm{H}_{2} \leftrightarrows \mathrm{CH}_{4}+2 \mathrm{H}_{2} \mathrm{O} \quad \Delta \mathrm{H}=-40 \mathrm{kcal} / \mathrm{mol} \\
\mathrm{CO}+3 \mathrm{H}_{2} \leftrightarrows \mathrm{CH}_{4}+\mathrm{H}_{2} \mathrm{O} \quad \Delta \mathrm{H}=-49 \mathrm{kcal} / \mathrm{mol} \\
\mathrm{n} \mathrm{CO}+(2 \mathrm{n}+1) \mathrm{H}_{2} \leftrightarrows \mathrm{C}_{\mathrm{n}} \mathrm{H}_{(2 \mathrm{n}+2)}+\mathrm{n} \mathrm{H}_{2} \mathrm{O} \\
\Delta \mathrm{H}=-49 \mathrm{kcal} / \mathrm{mol}(\mathrm{n}=1)
\end{gathered}
$$

Figure 1 shows such an operational system developed by Pioneer Astronautics combining a steam reformer and Sabatier reactor (Ref. 13). Alternatively, a one-step approach can be pursued, typically relying on endothermic processes that can be fueled by heat supplied by combustion of volatile low-carbon by-products (C1-C4) that are not suitable as propellants; see for example Figure 2 showing an operational thermal cracking or pyrolysis unit developed by RES Polyflow (Ref. 13). These tertiary "cracking" processes are also referred to as chemical recycling (Ref. 11) and are much simpler from a reaction engineering and system perspective but produce relatively large amounts of solid waste or char and are not suitable for a nonterrestrial or minimally-attended environments relevant for space exploration (Refs. 1 to 8 ).

A third process that captures elements of steam reforming and pyrolysis is flash cracking of plastic waste into tunable molecular weight fuels. This technology, being developed by Aerodyne Research, Inc., "flashes off" desired hydrocarbon products as they form, thus preventing the over-cracking of the polymers into more volatile hydrocarbons (Ref. 20). Key advantages of this innovation are 1) improved selectivity for low vapor-pressure hydrocarbons, which are easier to store as fuel in large quantities at low pressures; 2) tunable molecular- weight products by changing operating conditions for multiple applications. Promising initial results suggest that this technology can be utilized to produce useful liquid fuels with tunable product distributions. It can also be easily modified for FischerTröpsch wax cracking during Fischer-Tröpsch synthesis (F-T(S)) to improve its overall conversion (Refs. 15 and 19).

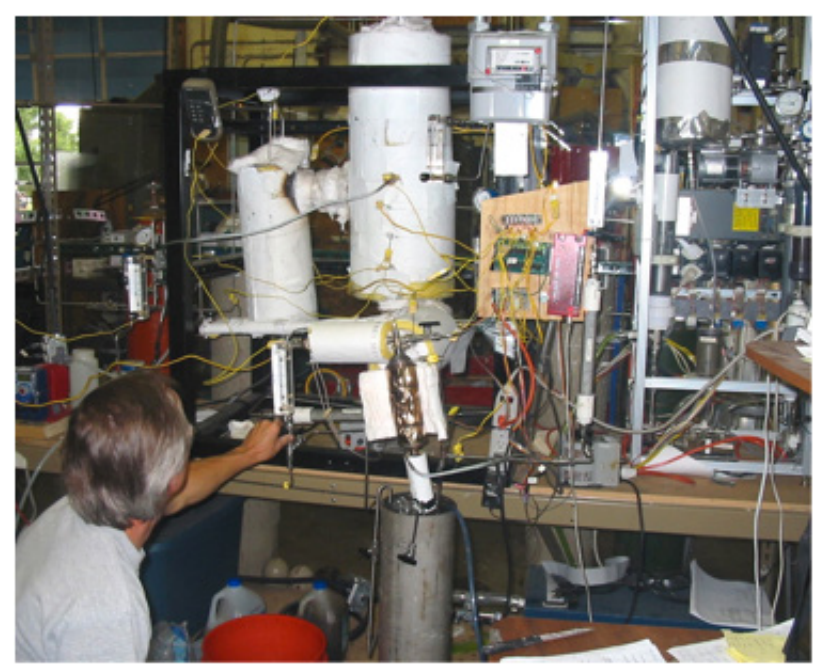

Figure 1.-Steam reformer/Sabatier reactor system delivered to GRC from SBIR Phase II contract.

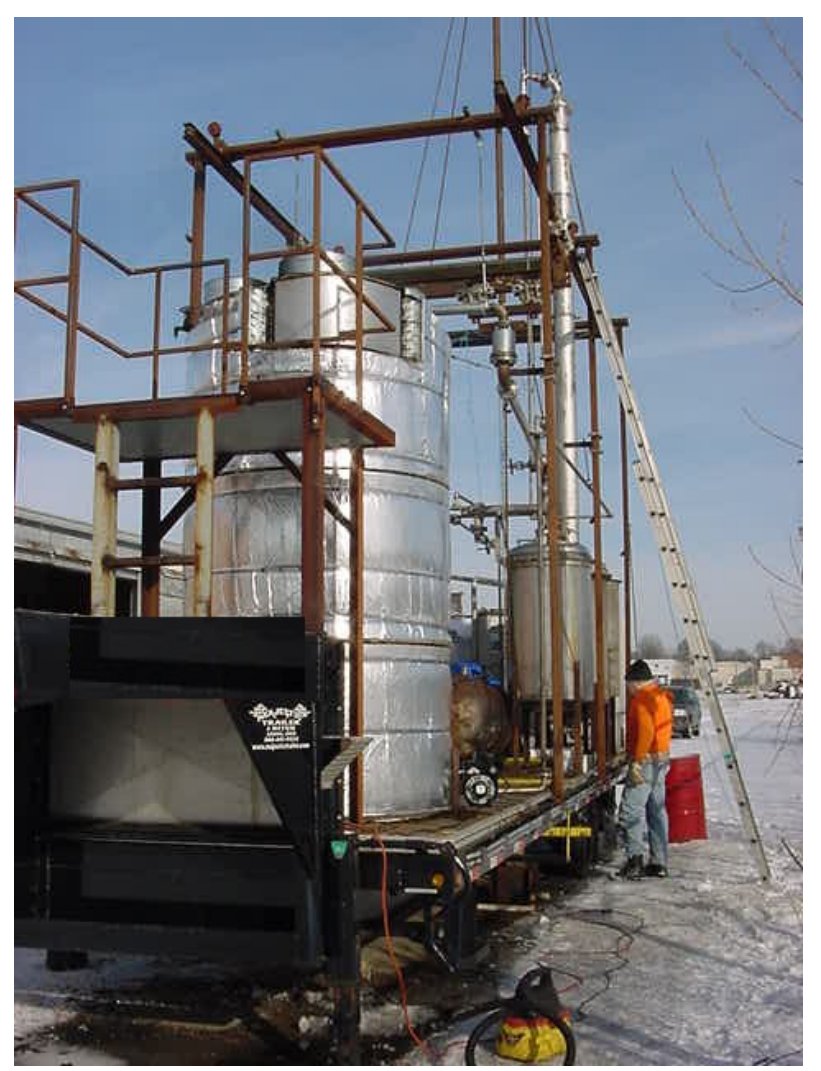

Figure 2.-Commercial pilot-scale reactor for chemical recycling. 


\subsection{Energy Efficiency Issues and Solar Concentrator Testing in a Simulated Lunar Setting}

Energy must be considered at a system level, where heat is added to the system for driving endothermic reactions ((1) (3)); heat is subsequently harvested from exothermic reactions ((4) - (6)) for improving overall system efficiency. Overall heat rejection must also be considered. Electric power derived from photovoltaics is a likely source of process energy, including the electrical energy needed for running pumps and splitting water. In certain cases there may be merit in considering solar thermal to augment the process energy, particularly for endothermic reforming reactions.

Given a Sun-tracking requirement, solar thermal augmentation may best be suited for treatment facilities that are anchored to the lunar or Martian surface rather than part of a spacecraft rotating about its axis for thermal control. Numerous studies have been completed on the various types of solar thermal concepts available for possible use, ranging from rigid structures having facets with high quality optical surfaces and concentration ratios of the order of 8000:1, to concepts that tout light weight inflatable structures, light pipes, and trough systems with lesser efficiency and lesser concentration ratios (Refs. 5, 21, and 22).

A recent successful demonstration of a solar concentrator for an ISRU-based application involved running a carbothermal reactor in a simulated lunar environment (Ref. 5). The carbothermal reduction method uses a temperature of at least 1800 $\mathrm{K}$ to extract the $\mathrm{O}_{2}$ from all the major constituents of the lunar regolith. The carbothermal reactor must melt the regolith to start the reaction; this melt is achieved by heating a small amount of regolith and using the surrounding regolith as insulation. Concentrated solar energy is used to melt the regolith. Excess space above the regolith is used to flow the reacting gas, $\mathrm{CH}_{4}$. The gas reacts with the molten regolith to produce water, which is then electrolyzed to produce $\mathrm{O}_{2}$ and $\mathrm{H}_{2}$. The $\mathrm{H}_{2}$ gas is reused in the process to regenerate $\mathrm{CH}_{4}$.

The solar energy is focused through a window into the reactor chamber. There are other methods that could be implemented to focus concentrated solar energy onto the regolith, including heat pipes or fiber optic cables. There are some potential design concerns with each of these approaches. For example by using a window to let concentrated sunlight into the chamber the window could be obscured by regolith particles in the reactor clinging to the window. Also the chamber has free flowing gas, which could pick up dust and interfere with the focusing of light. It should be noted that a sufficient gap is required between the regolith and window otherwise, the temperature gradient across the window can cause excessive thermal stresses potentially causing failure. Deposits on the end of the quartz rod will absorb some of the concentrated solar energy, both attenuating the solar energy delivered to the regolith and quickly heating the quartz rod until failure.
An Orbital Technologies Corporation (ORBITEC) Carbothermal Regolith Reduction Module (CRRM) was initially tested with a $\mathrm{CO}_{2}$ laser to simulate concentrated solar energy (Ref. 23). The $\mathrm{CO}_{2}$ laser energy passed through a zinc selenide ( $\mathrm{ZnSe}$ ) window and illuminated a bed of lunar regolith simulant located at the bottom of the sealed processing chamber within the CRRM. The laser energy absorbed by the regolith simulant caused rapid, localized heating. If laser energy flux was high enough, a pool of molten simulant would form surrounded by unmelted simulant due to the low thermal conductivity of regolith simulant. The surface temperature of molten simulant was determined by the laser energy flux. This heating approach worked well as long as the $\mathrm{ZnSe}$ laser window remained completely clean during operation. Surface temperatures of the molten regolith simulant in excess of $1800{ }^{\circ} \mathrm{C}$ were easy to achieve and maintain.

A solar concentrator system developed by Physical Sciences Inc. (PSI), was integrated with the ORBITEC CRRM (Ref. 24). The integrated system was successfully operated for nearly two weeks during the January 2010 International Lunar Surface Operations and ISRU Analog Test on Mauna Kea in Hawaii shown in Figure 3. Concentrated solar energy was delivered into the processing chamber through a quartz rod; since the temperature of the regolith surface was determined by the flux of the solar energy, varying the distance of the quartz rod above the regolith controlled the regolith temperature. Similar to the $\mathrm{ZnSe}$ laser window, the quartz rod efficiently transmitted the concentrated solar energy into the processing chamber when it was clean. Further development is required to optimize the efficiency of this unit operation.

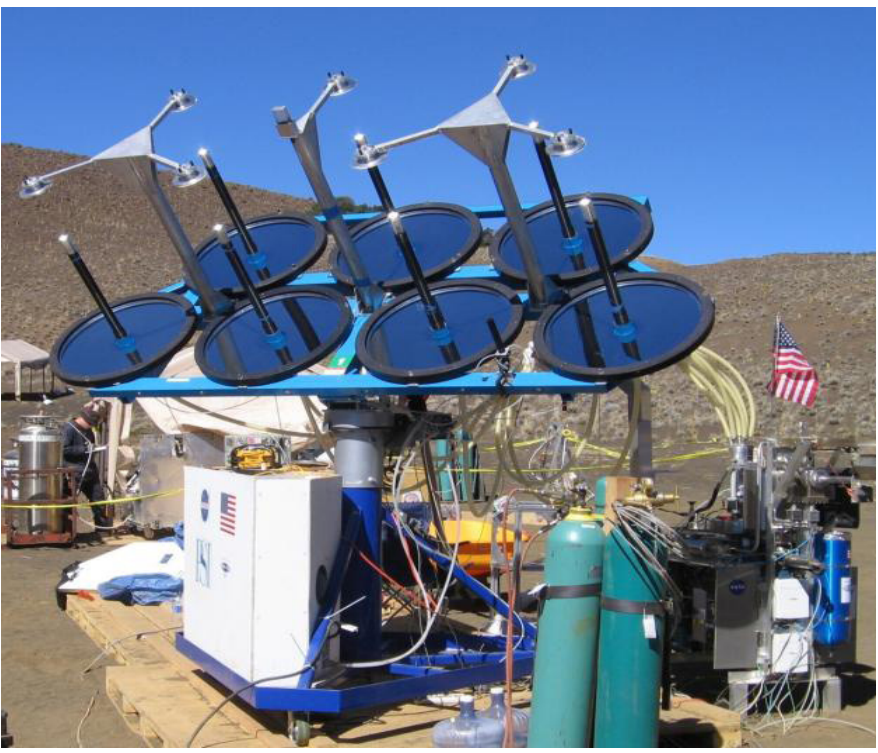

Figure 3.-Integrated Carbothermal Regolith Reduction reactor integrated to a solar energy collection and delivery module developed on SBIR contracts-successfully demonstrated on a mountainside in Hawaii. 
While use of concentrated solar power for processing of insitu resources is attractive for lunar installations, Martian applications are less attractive, owing to the greater distance from the Sun, the prevalence of dust storms, and wind loading on structures (Ref. 25). Use of concentrated solar power on a deep space habitat is problematic, given the anticipated rotisserie motion of the spacecraft needed for thermal control. Autonomous mining of near Earth asteroids is another potential use for concentrated solar power, where core samples carved from an asteroid are directed into a high temperature reactor to recover volatiles. Recovering iron $(\mathrm{Fe})$ or precious metals may be another possible use for concentrated solar power.

Finally, as we reconsider systems designs, shuttling of excess heat from exothermic reactions to power endothermic reactions may be possible utilizing conventional heat pipes or heat exchangers designed to deliver such energy from one location to another (Refs. 5 and 21). However, a temperature gradient is needed in such systems, the processing temperatures may limit such a concept, and losses are inevitable. Heat pumps are available to shuttle excess heat from one location to another, with the added feature of increasing the temperature at the outlet. Of course, heat pumps represent an electric load on the system and must be incorporated into any energy balance study. Perhaps the ideal concept is one where sufficient electrical power is provided to the reactor into which reactants are provided to overcome the sensible heat of the reactor mass and the energy needed to initiate endothermic reactions during transient startup operations, and electrical power is throttled back as new solar thermal heat sources are brought on line during steady state operation. Repeated transient and steady state operation should be expected for either batch or continuous processing, though far fewer cycles would be anticipated for a continuous reactor (Ref. 5).

\subsection{Transformation of Raw Materials: Cross Fertilization of Terrestrial and ISRU Technologies}

There have been numerous excellent reviews that summarize and analyze in detail the various technologies, products, energy balance, and economics of several mainstream terrestrial wasteto-energy (WTE) technologies; relevant reactions can be considered as tertiary (includes longer-chain products: typically C5 or higher) or quaternary processes (shorter-chain, typically $\mathrm{C} 1$ to C4 products) (Ref. 11). For space exploration, NASA's Logistics Reduction and Repurposing (LRR) program addresses a similar technical problem of waste utilization but on a much smaller scale. On a deep space mission, each astronaut will generate a waste stream of about one $\mathrm{kg} /$ per day, consisting primarily of organics suitable for decomposition into carbon, $\mathrm{O}_{2}$, and $\mathrm{H}_{2}$. In-flight utilization of waste and trash to produce essential materials such as water, fuel(s), and $\mathrm{O}_{2}$ is an anthropogenicwaste application of an ISRU approach for sustainability. For prudent and efficient utilization of terrestrial raw materials and energy for transportation fuel production, re-use or recovery of hydrocarbons from waste materials or gas flares is increasingly integrated into process design(s) (Refs. 5, 11, and 26).

The LRR program considered a number of processes that have been explored for potential use as reactions for the conversion of the waste into useful products, including incineration, steam reforming, pyrolysis, catalytic wet air oxidation, and ozonation (Ref. 12 and 20). A comparison of relevant technical details as well as energy utilization for several representative processes and suitability for potential use in mobile platforms, terrestrial applications or space missions is detailed in Table I. The list of processes considered includes primary (more energy

TABLE I.-COMPARISON OF RELEVANT METRICS FOR WASTE HANDLING PROCESSES

\begin{tabular}{|c|c|c|c|c|c|}
\hline $\begin{array}{l}\text { Process } \\
\text { (type) }^{\mathrm{a}}\end{array}$ & $\begin{array}{l}\text { Temperature; pressure } \\
(\mathrm{MPa}) \text { range(s) }\end{array}$ & Product Output & $\begin{array}{l}\text { Technical } \\
\text { complexity }\end{array}$ & Energy efficiency or utilization & $\begin{array}{l}\text { Appropriate } \\
\text { application(s) }\end{array}$ \\
\hline Thermal cracking $(\mathrm{T})$ & $\begin{array}{c}400 \text { to } 450{ }^{\circ} \mathrm{C} \\
4 \text { to } 6.9\end{array}$ & $\begin{array}{c}\text { C1-C5 } \\
\text { Mostly > C6 } \\
\text { Hydrocarbons }\end{array}$ & Low & $\begin{array}{l}\text { Burning C1-C5 fraction supplies } \\
80 \% \text { energy }\end{array}$ & $\begin{array}{l}\text { Chemical recycling } \\
\text { plant }\end{array}$ \\
\hline Flash cracking (T or Q) & $\begin{array}{c}400 \text { to } 600{ }^{\circ} \mathrm{C} \\
0.1 \text { to } 1.0\end{array}$ & $\begin{array}{c}\text { Flexible: } \mathrm{C} 1-\mathrm{C} 10 \text { depending upon } \mathrm{T} \text {, } \\
\text { P, catalyst }\end{array}$ & Medium & $\begin{array}{l}\text { Designed to be low energy; } \\
\text { potential solar energy use }\end{array}$ & $\begin{array}{l}\text { Recycling or mo- } \\
\text { bile/ISRU }\end{array}$ \\
\hline Photocatalysis (Q) & $\begin{array}{c}25{ }^{\circ} \mathrm{C} \\
0.1\end{array}$ & $\begin{array}{l}\text { Oxygenated C1-C5 depends upon } \\
\text { time, light energy and photocatalyst }\end{array}$ & Low $^{b}$ & $\begin{array}{l}\text { Low energy; relies on solar energy } \\
\text { use }\end{array}$ & $\begin{array}{l}\text { Municipal water or } \\
\text { auxiliary for ISRU }\end{array}$ \\
\hline $\begin{array}{l}\text { Catalytic wet air oxidation } \\
\text { (Q) }\end{array}$ & $\begin{array}{c}200 \text { to } 350{ }^{\circ} \mathrm{C} \\
2.0 \text { to } 20\end{array}$ & Syn-gas $\left(\mathrm{CO}+\mathrm{H}_{2}\right), \mathrm{CO}_{2}, \mathrm{CH}_{4}$ & Medium $^{\mathrm{b}}$ & $\begin{array}{l}\text { Designed to be low energy; } \\
\text { potential solar energy use }\end{array}$ & $\begin{array}{l}\text { Auxiliary process for } \\
\text { ISRU }\end{array}$ \\
\hline Steam reforming $(\mathrm{Q})$ & $\begin{array}{c}\sim 850{ }^{\circ} \mathrm{C} \\
0.3-0.7\end{array}$ & Syn-gas $\left(\mathrm{CO}+\mathrm{H}_{2}\right), \mathrm{CO}_{2}, \mathrm{CH}_{4}$ & Medium $^{\mathrm{b}}$ & $\begin{array}{l}\text { Balancing endothermic and } \\
\text { exothermic reactions }\end{array}$ & Mobile/ISRU \\
\hline PAG (Q) & $\begin{array}{c}\sim 5,000{ }^{\circ} \mathrm{C} \\
0.1\end{array}$ & $\begin{array}{l}\text { Primarily } \\
\text { Syn-gas }\end{array}$ & $\operatorname{High}^{\mathrm{b}}$ & $\begin{array}{l}\text { Recovery of Thermal energy from } \\
>1000^{\circ} \mathrm{C} \text { syn-gas stream }\end{array}$ & Municipal power \\
\hline
\end{tabular}

${ }^{a}$ Chemical Recycling (T/Tertiary) or Energy Recovery (Q/Quaternary).

${ }^{\mathrm{b}}$ Needs to be combined with a secondary process to produce fuels. 
intensive) processes such as thermal cracking, flash cracking, steam reforming, and plasma assisted gasification (PAG) technologies; for comparison, auxiliary processes - photocatalysis (Ref. 27) and catalytic wet air oxidation (CWAO) (Ref. 28) are included.

An example of a thermal cracking or pyrolysis chemical recycling technology being developed by (among others) an Akron, Ohio-based, start-up company (RES Polyflow) is shown above in Figure 2. The RES Polyflow pyrolysis process is quite simple but scalability may be an issue for space utilization. However, an interesting potential application of this technology could be as the key process to enable a fleet of sea-going vessels to collect and process islands of plastic waste or marine litter (Ref. 29) that are currently gathering in various places on the oceans and are thought to pose a potential long-term pollution issue. Using solar thermal and solar electric energy along with selling the chemical feedstocks and fuels produced would defray costs and possibly produce a near break-even or profitable enterprise.

As discussed above, a flash cracking reactor is quite flexible from a process perspective and hence is somewhat similar to FTS, the most flexible of the secondary processes of synthesis or producer gas conversion. The final product mix can be tailored depending upon the temperature and pressure as well as the presence of a catalyst (Ref. 30). The lower energy demand for this process can be met by solar thermal and photovoltaic sources; this aspect of system design was addressed in a generic sense above.

The steam reforming process can handle a broader (dirtier) feedstock and includes an integrated Sabatier process to produce $\mathrm{CH}_{4}$ but requires a $\mathrm{H}_{2}$ source. Pioneer Astronautics has combined two unit operations that work in tandem to produce $\mathrm{CH}_{4}$ and $\mathrm{O}_{2}$. The process is quite scalable and was delivered to GRC in Summer 2013 as a prototype unit (Figure 1) from a Phase II Small Business Innovative Research (SBIR) Program. One issue is the need for an external $\mathrm{H}_{2}$ source for a Sabatier reactor: this would most likely come from splitting water (Ref. 13). But on the whole, steam reforming offers the prospect of significantly reducing the waste plastics derived from LRR.

The rather complex plasma-assisted gasification process relies on high temperatures to recover thermal energies; it is included for the sake of comparison, and is currently only practical for larger-scale (municipal) use. While it is difficult to make direct comparisons regarding scale of infrastructure required, a typical plasma system requires significant balance-of-system hardware in order to enable self-sustaining electrical power. An energyefficient system will include reusing otherwise wasted thermal energy from stage-one products (i.e., syn-gas at $>1000{ }^{\circ} \mathrm{C}$ ) to drive turbines to generate electricity. This would then be followed by an F-T operation to convert syn-gas $\left(\mathrm{CO}\right.$ and $\left.\mathrm{H}_{2}\right)$ into a product soup of saturated and unsaturated hydrocarbons as well as some oxygenated products such as alcohols of $\mathrm{C} 5$ to $\mathrm{C} 20$ or so with some waxy materials. The balance-of-system technology requirements drive up the complexity (and cost), thus minimizing suitability for space applications (Ref. 31).

Finally, the Sabatier reaction (4), a century-old $\mathrm{CO}_{2}$ reduction process (Ref. 17), is considered an important part of the architecture for the human exploration of Mars (Ref. 25). A Sabatier reactor is already part of the Environmental Control and Life Support System (ECLSS) equipment on the International Space Station (ISS) to process $\mathrm{CO}_{2}$, primarily for its removal and water recovery. Utilizing a Sabatier reactor saves considerable mass in water resupply by diminishing the need for water upmass and substituting a significantly less massive resupply of $\mathrm{H}_{2}$. For ISS, the $\mathrm{CH}_{4}$ created is jettisoned overboard. However, for a deep space habitat, one could easily envision an additional treatment process where $\mathrm{H}_{2}$ is recovered from $\mathrm{CH}_{4}$ via pyrolysis at $1000{ }^{\circ} \mathrm{C}$. The byproduct of this additional step is pyrolytic graphite that could be utilized as filler or a conductivity-enhancing agent in the $3 \mathrm{D}$ printing of composite tools and hardware during a 400-day mission.

\subsection{Saltwater Desalination Using Solar Concentrators: A Terrestrial Case Study}

In an effort to provide fresh water through desalination in a clean, economical, and environmentally friendly way, a solar powered water desalination facility was considered. Selling the fresh water produced as well as the left over salt could pay for this facility. With a water production rate of $475,000 \mathrm{gal} /$ day the possible profit could be $\$ 9,000,000$ a year. However, the current costs of the solar concentrators alone were estimated to be over $\$ 260,000,000$. The process could become feasible if the solar concentrator price per unit were to be reduced.

\subsection{The Oceans as a Potential Resource}

Fresh water shortages are a major concern in many places around the world. With growing human populations, these sources are being severely taxed. People are now looking towards other possible sources for potable water. One major source could be the oceans. Consisting of approximately 97 percent of Earth's water, the oceans could provide all the water needed by expanding populations (Ref. 29). However, before seawater can be usable, it must first be desalinated. This is naturally done by evaporation due to the solar energy on the surface of the water sources such as the oceans. The evaporated water later falls back to the Earth as rain. Increasing the heat energy to the water and then capturing evaporation can accelerate this process. The problem with this approach is in the amount of energy required to quickly evaporate water. 
However, it is possible to utilize solar energy through solar concentrators to provide the energy required. Furthermore, sea salt has recently become a desirable commodity. After the water has been evaporated, the remaining salt can be collected and sold to help offset costs of the desalination process. This helps to resolve an issue related to dumping concentrated brine into the ocean: the ecosystems will not be affected since isolated salt is collected for sale. Furthermore, using solar concentrators provides a clean renewable energy source (Ref. 5).

\subsection{Process Overview}

The desalination process discussed in more detail below had two objectives. The first was to provide fresh water. The second was to extract the sea salt for the added profit. A diagram of the process can be seen in Figure 4. The steps in the process are as follows:

- Seawater was transported from the ocean to the desalination site.

- The seawater entered a heat exchanger to raise its temperature.

- The warmed seawater would then enter the boiler (powered by solar concentrators) where 95 percent would be evaporated.

- The evaporated steam would pass through the heat exchanger to condense back into water, while the salt and remaining water would be transported to the salt evaporation beds.

- The condensed steam would be stored until it was transported to its final location.

\subsection{Location Selection}

The ideal location for the desalination plant would be on the coast in an area with an abundance of sunlight. Several locations were considered depending on their distance from the coast and the amount of sunlight received. The main consideration for the distance was the amount of power needed to move the water. Only two aspects of the flow were considered for water transportation (the change in height and the headloss). The headloss depended on the pipe material and the flow through the pipe. The first step to calculate the headloss was to determine the Reynolds number of the flow (Re), which can be found by Equation (7)

$$
\mathrm{Re}=\frac{\rho v D}{\mu}
$$

where $\rho$ is the density of the water, $v$ the velocity of the flow, $D$ the diameter of the pipe, and $\mu$ the dynamic viscosity of the water.
The Reynolds number along with the roughness of the pipe (assumed polyvinyl chloride (PVC)) was then used to determine the fouling factor of the pipe $(f)$, see Equation (8), where $\varepsilon$ was the roughness of the pipe. The flow was assumed to be turbulent, since the turbulent flow was more power intensive and in most cases was indeed turbulent. The head-loss $\left(h_{l}\right)$ was then determined by Equation (9). The power required to move the water was dependent on the headloss and the height the water needed to be lifted to reach the site. The relation used, assuming no change in pressure and a constant flow is (10).

$$
\begin{gathered}
f=\sqrt{\frac{1}{-1.8 \log \left[\left(\frac{\varepsilon / D}{3.7}\right)^{1.11}+\frac{6.9}{\mathrm{Re}}\right]}} \\
h_{l}=f \frac{L}{D}\left(\frac{v^{2}}{2 g}\right) \\
\dot{w}_{p}=\left(z+h_{l}\right) \dot{m} g
\end{gathered}
$$

The chosen location would therefore dictate the amount of power needed to transport the saltwater, which would depend on the distance and the height relative to the water source. The other major consideration was the amount of sunlight received. Since solar concentrators were used to provide the energy to boil the water, an area that is nearly free from clouds year round was preferable. Therefore, the best locations that were identified are found in Table II. To compare the locations equally, the same amount of water was considered for each. Table III gives the initial assumptions in order to produce about 475,000 gal/day.

TABLE II.-LOCATIONS FOR A SOLAR CONCENTRATOR POWERED WATER DESALINATION FACILITY

\begin{tabular}{|l|c|c|c|c|}
\hline \multicolumn{1}{|c|}{ Location } & $\begin{array}{c}\text { Sunshine, } \\
\%\end{array}$ & $\begin{array}{c}\text { Average } \\
\text { number } \\
\text { of clear } \\
\text { days }\end{array}$ & $\begin{array}{c}\text { Approximate } \\
\text { distance from } \\
\text { ocean, } \\
\mathrm{km}\end{array}$ & $\begin{array}{c}\text { Elevation, } \\
\mathrm{m}\end{array}$ \\
\hline Yuma, Arizona & 90 & 242 & 120 & 43 \\
\hline Fresno, California & 79 & 194 & 190 & 90 \\
\hline Sacramento, California & 78 & 188 & 100 & 8 \\
\hline Salton Sea, California & $\sim 80$ & N/A & Inland salt lake & -69 \\
\hline
\end{tabular}

TABLE III.-ASSUMED PIPE FLOW CONDITIONS

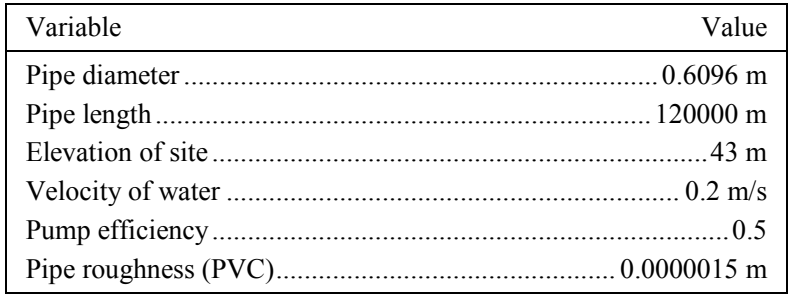




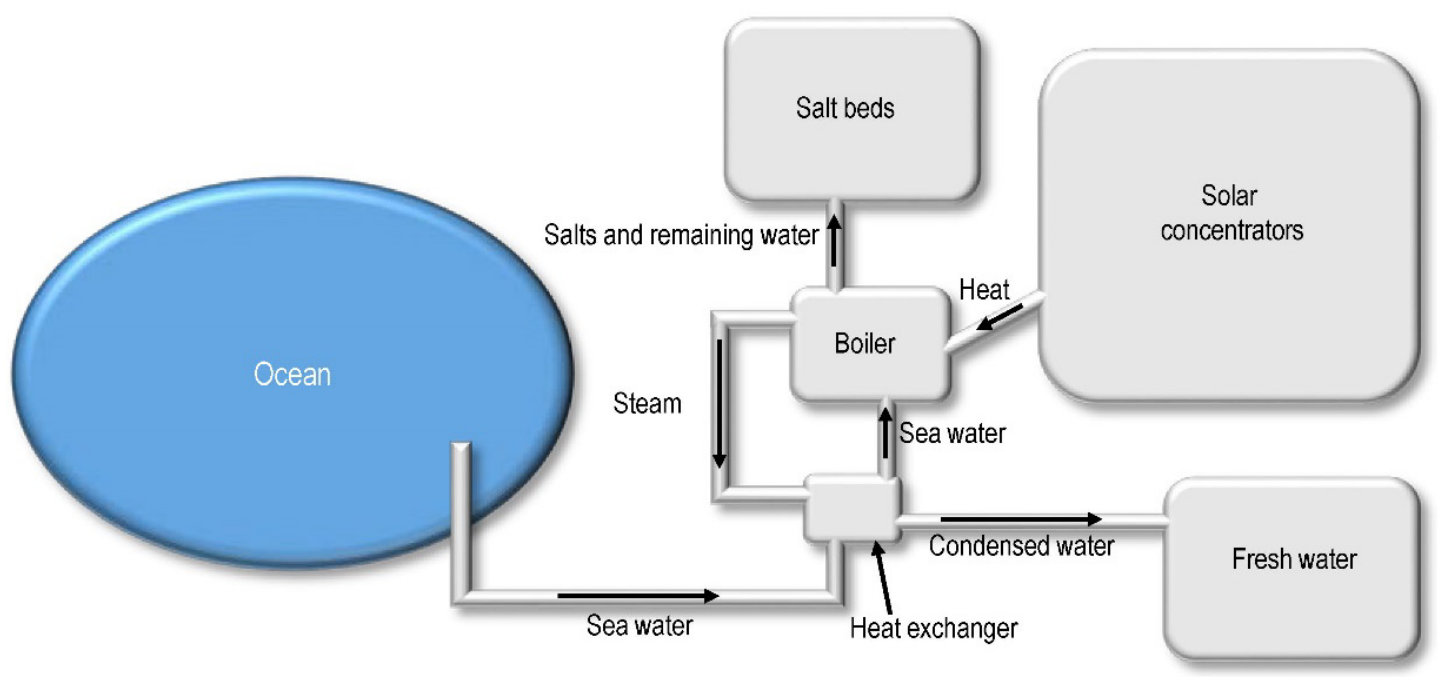

Figure 4.-Solar concentrator-powered Saltwater Desalination diagram.

Based on only the distance and elevation of the location with respect to the ocean, the best choice would appear to be the Salton Sea. However, the Salton Sea has been considered an important wetlands area and also has a limited supply of water (Ref. 32). If this water source were used, it could slowly be depleted. The best location turned out to be Yuma, Arizona. This was due primarily to the cost of the solar concentrators compared to the cost of pumping the water. Since Yuma had the most sunshine, fewer concentrators were needed to desalinate the same volume of water. Therefore, Yuma was selected as the location for further study.

\subsection{Power Requirements for Desalination}

The power requirements for desalination were calculated based on the power needed to bring the saltwater to the boiling point along with the heat of evaporation of the water. The assumed values used to calculate the power requirements can be found in Table IV. Since salt would increase the boiling point of water and the concentration of salt would increase as water boils, it was assumed that the boiling temperature was $115^{\circ} \mathrm{C}$. However, not all of the water was removed from the salt. The remaining water could be used to help flush out the salt. Since there was remaining water, the exiting water was a mixture of liquid and gas. The $\Delta \mathrm{H}$ of the mixture $(h)$ was determined by Equation (11); using the calculated $\Delta \mathrm{H}$ of the mixture, the thermal power required $(\dot{Q})$ was calculated by Equation (12).

$$
\begin{gathered}
h=h_{f}+x\left(h_{g}-h_{f}\right) \\
\dot{Q}=\dot{m} c_{p w}\left(1-x_{s}\right)\left(T_{i}-T_{o}\right)+\dot{m} x_{s} c_{p s}\left(T_{i}-T_{o}\right)+\dot{m}\left(h-h_{f}\right)
\end{gathered}
$$

\section{TABLE IV.-CONSTANTS FOR WATER EVAPORATION}

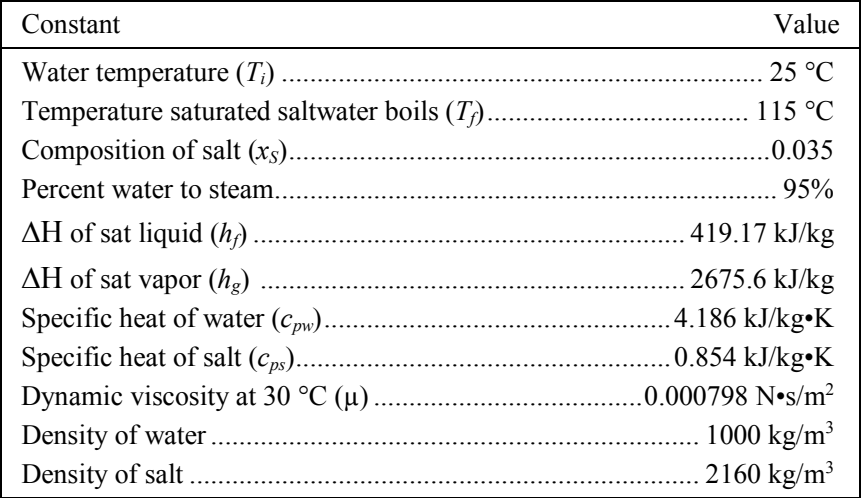

The total thermal power comes from the power required to heat the water, to heat the salt, and to evaporate the water up to obtain the desired weight-percentage of salt. This power came directly from the solar concentrators. The left over saltwater mixture would be transported to a series of evaporator beds, which would allow natural evaporation to remove the remaining water.

\subsection{Solar Concentrators}

The main concept of a solar concentrator was to take a large area irradiated by solar energy and compress it to a smaller area. This directly makes use of the thermal energy available from the Sun to heat the water. The thermal energy depends on a few factors such as the location and time of year. A location in the desert south of Yuma was chosen for the availability of sunlight. The location was approximately latitude $32.5^{\circ} \mathrm{N}$ and longitude $114.5^{\circ} \mathrm{W}$. These were used with an insolation program available online to give the available insolation depending on the day, month, and year (Ref. 33). The value for each day in 
2009 was used to determine the average insolation, which was used for calculations. This means in winter less water would be desalinated; in summer more water would be desalinated. The average insolation was $331.6 \mathrm{~W} / \mathrm{m}^{2}$, and the total power needed was $146.5 \mathrm{MW}$. The solar concentrator considered was one designed and build for NASA (Ref. 5). The concentrator was approximately $11 \mathrm{~m}^{2}$ and can track the Sun's movements throughout the day.

\subsection{Estimated Costs}

The unit costs to buy or sell different items can be found in Table V. The costs were broken up into three categories: one time startup cost, yearly expenditures, and yearly income. A breakdown of each can be seen in Figure 5 to Figure 7. The biggest expense was in the cost of the concentrators. The estimated cost ( $\$ 5000$ per concentrator) was assumed to be achievable with mass production. However, the price may need to drop further for the setup cost to be reasonable. The pump cost is the total cost of electricity needed to transport the seawater. The remaining was the assumed operation and maintenance costs.

It can be seen in Figure 7 that the bulk of the income comes from the sale of sea salt due to its high selling price. This could actually cause the desalination facility to become a sea salt producing facility with fresh water being a byproduct, instead of a water facility with sea salt as a byproduct. The estimated yearly operating cost is completely covered by the income generated from selling the water (operating expense $=\$ 107,328$ and water income $=\$ 220,886$ ). This would leave the entire sale of sea salt as profit year to year. However, this profit must first go towards covering the startup costs. Assuming an extremely low interest rate of 1 percent yearly, it would still take 30 years to pay off the initial debt, which leaves no room for expansion or replacement of worn out concentrators for that 30 year period.

TABLE V.-ESTIMATED UNIT COSTS

\begin{tabular}{|l|c|c|c|}
\hline \multicolumn{1}{|c|}{ Unit } & $\begin{array}{c}\text { Cost, } \\
\$ / \text { unit }\end{array}$ & $\begin{array}{c}\text { Number of } \\
\text { units }\end{array}$ & $\begin{array}{c}\text { Total, } \\
\$\end{array}$ \\
\hline Concentrators & 5,000 & $52,196.6$ & $260,983,140$ \\
\hline Pipe, m & 34.48 & 120,000 & $4,137,931$ \\
\hline Water, gal & 0.0015 & $147,257,380$ & $220,886.07$ \\
\hline Sea salt, kg & 0.5 & $10,268,444$ & $5,134,222$ \\
\hline Electricity, kWh & 0.0865 & $331,377.6$ & $28,664.16$ \\
\hline Evaporator beds, $\mathrm{m}^{2}$ & 10 & $2,499.46$ & $24,994.61$ \\
\hline Land, acre & 406.25 & 162.86 & $66,162.10$ \\
\hline
\end{tabular}

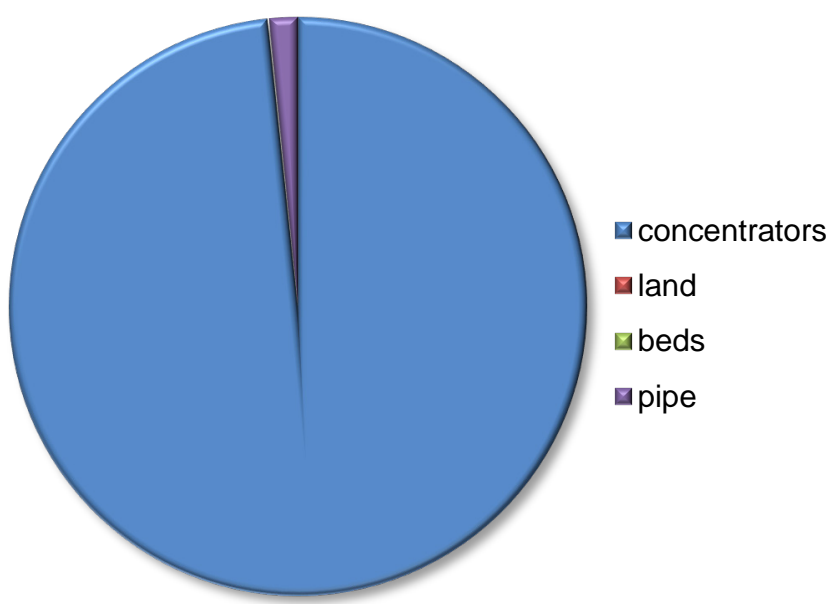

Figure 5.-Breakdown of startup expenses.

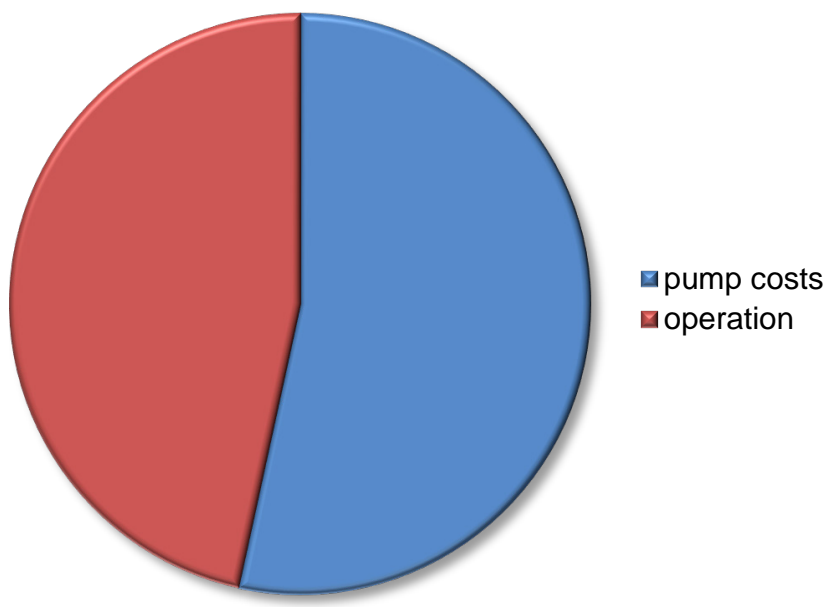

Figure 6.-Breakdown of yearly operating costs.

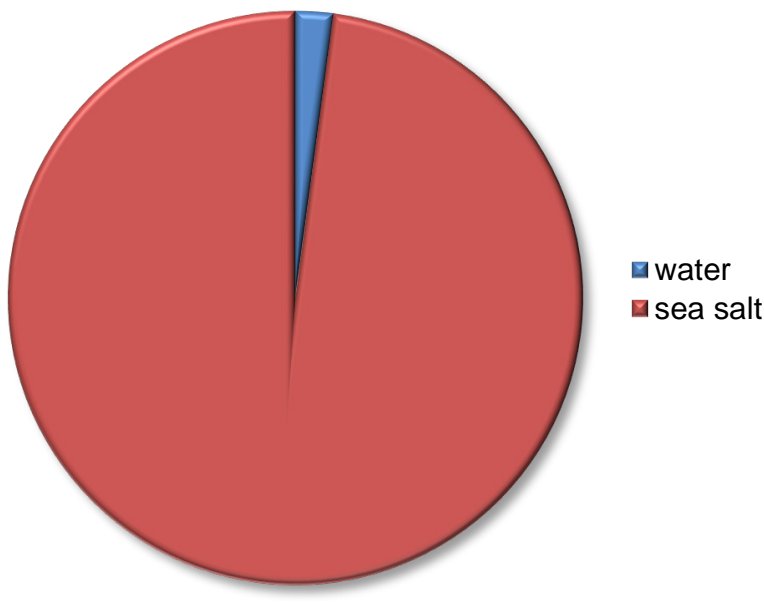

Figure 7._Breakdown of yearly income. 


\subsection{Pipe Flow}

There were two costs associated with transporting seawater. One was the reoccurring pumping costs, and the other was the cost of the actual pipe. The piping used was PVC, since any metal pipe would have heavy corrosion problems due to the saltwater. In order to allow for expansion and to reduce pumping costs, a large diameter $(0.6096 \mathrm{~m})$ pipe was chosen. However, this pipe may not be large enough to carry the $128,000,000 \mathrm{gal} /$ day that some of the larger desalination plants process (Ref. 34). To produce 128,000,000 gal/day of fresh water would require over $\$ 2$ billion in electricity per day just to pump in the water. This is obviously impractical, but the optimum point has yet to be calculated. To reach a production rate of $128,000,000 \mathrm{gal} /$ day would therefore require multiple pipelines to be within reasonable limits.

\subsection{Case for Solar Concentrator Technology to Produce Clean Water}

A water desalination facility powered by solar concentrators would be able to fund itself during operation, assuming public financing covered costs for the plant. However, unless the capital equipment costs of solar concentrators decrease, the facility would not be able to recoup the initial startup cost. Nevertheless, the system would still save money in the long run. Using the average cost of electricity in Arizona $(0.0865 \$ / \mathrm{kWh})$, the total cost of the solar concentrators would equal about 6.6 years worth of electricity running off the power grid for the same amount of power (not accounting for losses in converting electrical power to thermal). Furthermore, this process makes use of a clean renewable resource (the Sun) to provide needed freshwater.

\subsection{Resource Utilization on the Moon}

Oxygen is the highest-value resource to be produced on extraterrestrial bodies such as the Moon (Refs. 1 and 2), since it is the oxidizer component of rocket propellant, and is, for most chemical rocket types, the most massive component of the fuel used for propulsion. Thus, production of $\mathrm{O}_{2}$ from local material fuels the transportation system that supports the lunar base, as well as serving as a possible product for use in propulsion systems either commercially or to support exploration of other locations. Replacement $\mathrm{O}_{2}$ is also a necessary product for life support, since even closed-ecological life support systems will not have perfect efficiency of recycling.

In addition to the oxidizer, it would be desirable to produce the fuel as well. This is more difficult to produce from lunar material, since hydrocarbons are absent. The polar regions of the Moon are now understood to have permanently shadowed craters, in which water ice is present; this ice could be mined and then electrolyzed to produce $\mathrm{H}_{2}$ and $\mathrm{O}_{2}$, which can be used for fuel, although $\mathrm{LH}_{2}$ is difficult to store, requiring cryogenic tankage. The high latitudes of the Moon also contain water in the form of hydrated minerals. An alternate technology would be to develop rockets that do not utilize $\mathrm{H}_{2}$ or hydrocarbons. One alternative is metal propellants, such as aluminum (Al) or magnesium (Mg) (Ref. 3).

However, it will also be desirable to refine raw materials for other purposes, including structural materials and materials for industrial applications, such as production of solar arrays (Ref. 35). Many possible applications for lunar-produced materials are summarized by Benaroya (Ref. 36). The most desirable processing sequence therefore would focus on an initial goal of $\mathrm{O}_{2}$ production, but using a technique that could be expanded to produce and refine other raw materials.

Technologies for refining raw materials out of lunar regolith and rocks will also have applications on Earth. Terrestrial refining technologies used today require significant use of resources such as coal, energy, and water, and produce large amounts of waste byproduct such as $\mathrm{CO}_{2}$ and particulate pollution. Lunar resource extraction, on the other hand, must of necessity minimize the use of expendable resources, will recycle reactants and exhaust gasses, and will be optimized to be efficient in the use of energy. Thus, pilot production sequences for lunar resource utilization will serve as models for highly efficient, not-polluting technologies that can be utilized on Earth.

Workers at GRC have examined several methods of materials production from lunar regolith (Refs. 3, 35, 37, and 38). The same process sequences could be used at other locations. Stony asteroids typically have regolith similar to that of the Moon, and refining of asteroidal material could use the same techniques, adapted for microgravity. Other types of asteroids would allow processing possibilities not considered here. For example, Type-C asteroids contain carbon and can contain some amount of chemically bound water, which can be used for different purposes. Metallic asteroids can be processed to produce both bulk and precious metals. Likewise, Martian rock and soil could also be processed by the techniques discussed here.

\subsection{Desirable Products From Lunar Regolith}

Other than $\mathrm{O}_{2}$; and metals, glass, and related ceramics and $\mathrm{Si}$ are valuable as structural and power materials. Each subsection gives examples of practical applications of these materials for an eventual lunar colony.

\subsubsection{Metals}

Metals are a ubiquitous structural material, and will certainly be used in lunar manufacturing. Structural metals include Fe and steel, aluminum (Al), and titanium (Ti); each valuable for 
different uses, and all available as elemental components of lunar material. Metals are also used as wires conductors. From its elemental abundance in lunar soil and high electrical conductivity, Al is the clear choice for wires. A second possible choice is calcium, not used on Earth because of high reactivity with $\mathrm{O}_{2}$, but a possible conductor for vacuum applications.

\subsubsection{Glass and Ceramics}

Transparent glass is a required material in forming solar arrays (Ref. 35). Ceramics are also useful as insulators. Glass or ceramic fibers are useful for structural composites. The primary glass-forming material, silicon oxide, is abundant on the Moon, in the form of silicates. Transparency requires refining, most particularly to remove trace amounts of $\mathrm{Fe}$ and other transitionmetal oxides, which produce color centers. Silicon dioxide is not only a simple formula for glass but an engineered material with many additives selected to produce required properties. Several of the oxides which are used to adjust the properties of glass are not abundant on the Moon. Sodium oxide $\left(\mathrm{Na}_{2} \mathrm{O}\right)$, the main component of "soda lime glass," is typically used to reduce the melting point, allowing easier working. Boron oxide $\left(\mathrm{B}_{2} \mathrm{O}_{3}\right)$, to produce borosilicate glass, is typically used to adjust the thermal expansion coefficient. New glass compositions will have to be invented to reduce, or eliminate, the amounts of these materials that are rare in lunar soil.

\subsubsection{Silicon}

One of the most important issues for settlement is production of power. Many different semiconductors can be used to produce photovoltaic cells, but from the standpoint of lunar abundance of materials, the clear choice for locally-manufactured cells is Si solar cells (Ref. 39). Silicon suitable for semiconductor applications is a highly purified product; parts per billion of some impurities is sufficient to degrade the properties. Thus, a processing sequence for making solar-cell grade Si must include purification steps.

\subsubsection{Civil-Engineering Materials}

In addition to structural materials, lunar settlements will undoubtedly require less highly processed material. Although habitation structures on the Moon will not be made of ordinary bricks (since habitats must hold pressure, and hence will be tension structures), there will still be the need for the equivalent of concrete, asphalt, and bricks. Many possibilities for such bulk material exist, including sintered or melted regolith bricks, material produced from slag from other processes, or composite materials comprising aggregate fill cemented with a ceramic matrix.

\subsection{Processing Methods}

A processing sequence can be broken into three main steps: (1) Acquisition and beneficiation (if required) of feedstock; (2) Reduction; and (3) Refining of the desired raw materials and purification to the required level. What follows is a brief overview followed by a focus primarily on three different approaches to the second step, reduction.

\subsubsection{Processing Overview}

The acquisition portion of the processing is a sequence of prospecting (if required), materials acquisition and mining, grinding or otherwise preparing the material for processing, and (for some sequences) beneficiation of the input material to increase the concentration of the desired mineral. Preferably, the sequence selected could be fed from regolith that is available at any lunar location, minimizing and possibly eliminating the need for prospecting and for beneficiation.

The reduction step comprises stripping the $\mathrm{O}_{2}$ away from oxides. This step produces the main product, $\mathrm{O}_{2}$. Lunar regolith is primarily silicates, in which the oxides are in the form of $\mathrm{O}_{2}$ bridging between $\mathrm{Si}$ atoms, chemically bonded to metal cations in a strongly-bound net. The reduction process therefore requires breaking the $\mathrm{Si}-\mathrm{O}_{2}$ bonds.

After the $\mathrm{O}_{2}$ is produced, the byproduct is reduced (or partiallyreduced) metals. The resultant product may be a mixture of metals. To turn this into useable raw material, the desired materials must be separated and purified to the levels needed. Many sequences for $\mathrm{O}_{2}$ production have been previously reviewed (Refs. 1 to 3). Sequences of interest here are those that reduce the main components of lunar regolith, to produce metals.

\subsubsection{Magma Electrolysis}

Magma electrolysis is conceptually the simplest method of refining regolith into reduced metals and $\mathrm{O}_{2}$. It consists of heating lunar soil to the melting point, then running electrical current through the melt to electrolyze the anions (primarily $\mathrm{O}_{2}$ ) at one electrode, and the cations (metals and $\mathrm{Si}$ ) at the other (Ref. 36). However, the details are complicated. A significant difficulty is the extremely high temperatures needed, from 1300 to $14500^{\circ} \mathrm{C}$, which result in significant practical difficulties.

\subsubsection{Calcium Process}

A two-step calcium process is feasible as a method of reducing temperatures needed (Ref. 37). It requires considerably lower temperatures than direct magma electrolysis, and produces $\mathrm{O}_{2}$ with considerably higher efficiency than $\mathrm{H}_{2}$ or carbothermal reduction methods. The first step consists of reducing the regolith by calciothermic reduction. This is done 
by heating of regolith in the presence of metallic calcium, to convert the silicates into metals plus calcium oxide. Regolith is heated with metallic calcium at a temperature greater than the melting point of calcium, $845^{\circ} \mathrm{C}$. The reaction rate is increased by use of finely-ground reactants as well as excess calcium; Equation (13) shows a typical reaction:

$$
\mathrm{MgFeSiO}_{4}+4 \mathrm{Ca} \rightarrow 4 \mathrm{CaO}+\mathrm{MgFeSi}
$$

The second step (14) regenerates the metallic reactant, by electrolyzing the calcium oxide in a molten salt at 825 to $900{ }^{\circ} \mathrm{C}$, to produce metallic calcium and $\mathrm{O}_{2}$ :

$$
\mathrm{CaO} \rightarrow \mathrm{Ca}\left(\text { metal) }+1 / 2 \mathrm{O}_{2}\right. \text { (gas) }
$$

Since calcium and calcium oxide are soluble in calcium chloride $\left(\mathrm{CaCl}_{2}\right)$, the chloride or a $\mathrm{CaO} / \mathrm{CaCl}_{2}$ eutectic mix can be used as a flux to accomplish the reactions in a liquid solution. Further separation and purification steps can be taken from this point to produce refined product for other processing.

\subsubsection{Fluorine Process}

A basic reduction process requires heating regolith in the presence of fluorine. The fluorine displaces the $\mathrm{O}_{2}$ from the rock (collected as a useful product), producing fluorides. The fluorides are displaced by potassium to produce reduced metals and potassium fluoride (KF), which is electrolyzed (Refs. 35 and 38).

Silicon and Ti produce volatile fluorides, $\mathrm{SiF}_{4}$ and $\mathrm{TiF}_{4}$, both gaseous at processing temperatures. The tetrafluorosilane can be easily purified to semiconductor-grade by distillation. The remaining metals are produced in the form of fluoride salts, which must be reduced to the metals. The $\mathrm{Fe}$ and $\mathrm{Al}$ fluorine salts are directly reduced with potassium:

$$
\begin{aligned}
& \mathrm{FeF}_{3}+3 \mathrm{~K} \rightarrow 3 \mathrm{KF}+\mathrm{Fe} \\
& \mathrm{AlF}_{3}+3 \mathrm{~K} \rightarrow 3 \mathrm{KF}+\mathrm{Al}
\end{aligned}
$$

Calcium and magnesium fluorides are not reduced by potassium, and are returned to oxide form by potassium substitution:

$$
\begin{aligned}
& \mathrm{CaF}_{2}+\mathrm{K}_{2} \mathrm{O} \rightarrow 2 \mathrm{KF}+\mathrm{CaO} \\
& \mathrm{MgF}_{2}+\mathrm{K}_{2} \mathrm{O} \rightarrow 2 \mathrm{KF}+\mathrm{MgO}
\end{aligned}
$$

The oxides are then available for glassmaking. The reactants, fluorine and potassium, are returned in the form of $\mathrm{KF}$, and are then recovered by electrolysis in a $\mathrm{KF} / \mathrm{NaF} / \mathrm{CaF}_{2}$ eutectic at $676^{\circ} \mathrm{C}$.

\subsection{Impact of Geographical Location}

On the lunar surface there are two main types of soils available. These consist of the older, brighter soils at high topographies, termed highlands, and the darker basaltic lava flows of the mare located at lower topographies (Ref. 4). A display of the topography on the Moon is shown in Figure 8 (Ref. 40). The regolith at the highlands and mare have different compositions and therefore different $\mathrm{O}_{2}$ production processes are applicable to each of these areas. The $\mathrm{H}_{2}$ reduction process for producing $\mathrm{O}_{2}$ can yield 1 to 5 percent of $\mathrm{O}_{2}$ per unit volume of ilmenite (Ref. 24). For comparison the carbothermal $\mathrm{O}_{2}$ production process requires high enough temperatures to melt the regolith $(\sim 1800 \mathrm{~K})$, but can be used with most of the metal oxide compounds found in the regolith. The $\mathrm{O}_{2}$ yield of the process is approximately 15 percent by weight (Ref. 4).

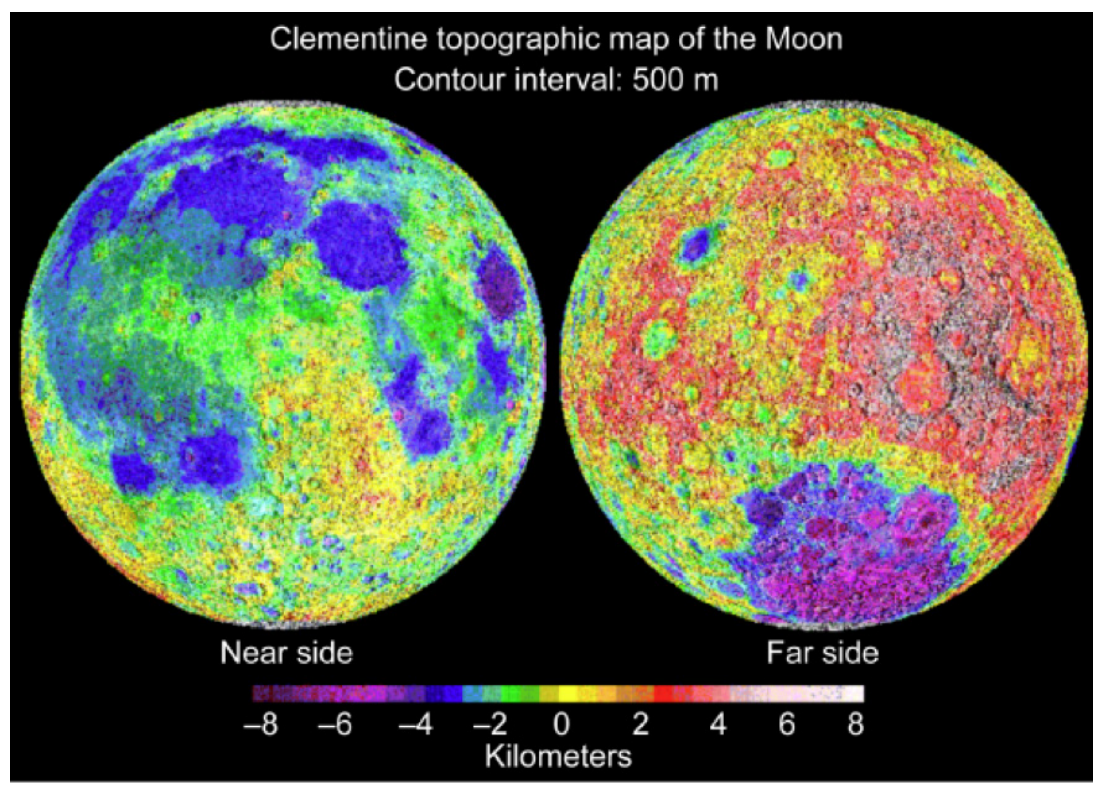

Figure 8.-Topographic map of the Moon determined by the Clementine mission of 1999. 


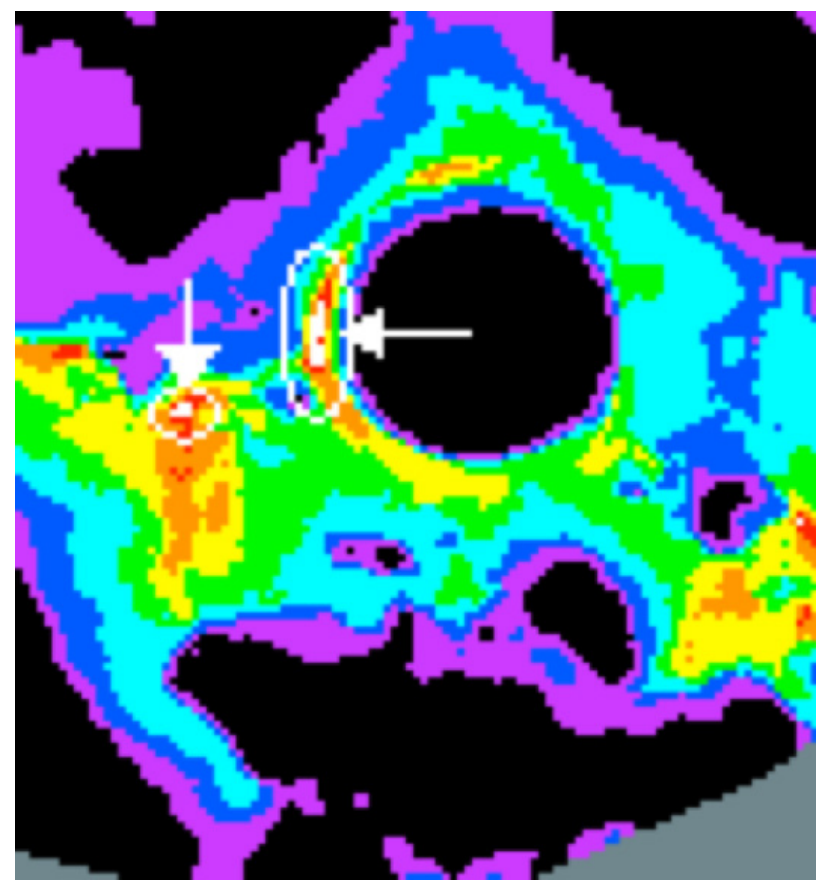

Figure 9.-Percentage of time with solar illumination during lunar winter. The arrows are pointing at the two regions that are illuminated $>70$ percent of the time during lunar winter; near the Shackleton Rim.

For locations within the mare regions, either $\mathrm{H}_{2}$ reduction or carbothermal reduction can be used as an $\mathrm{O}_{2}$ production process. Since ilmenite is not found in usable amounts in the highland regions (Ref. 41), the carbothermal process would be utilized within these regions. This means higher temperatures and more precise concentrator optics are required.

Though both the mare and the highlands have different regolith characteristics, they both have one significant problem; for approximately 14 Earth days, most of the mare and highland topographies are enshrouded in darkness (Ref. 42). Because the Moon's axis is angled $1.5^{\circ}$ from the ecliptic, the South Pole is almost constantly bathed in sunlight; during lunar summer, the entire South Pole is visible, and during lunar winter, the Shackleton crater and other small southern regions are illuminated by the Sun for more than 70 percent of the time (Ref. 42).

Figure 9 shows the percentage of time regions near the South Pole geographies are illuminated during lunar winter. Such areas would be an ideal place for a constantly operating solar concentrator that could generate approximately twice the amount of $\mathrm{O}_{2}$ than an ISRU system anywhere else on the Moon. However, there are minimal deposits of $\mathrm{Fe}$ and $\mathrm{Ti}$ located at the poles (Ref. 41). Less than 1 percent of ilmenite is present which means $\mathrm{H}_{2}$ reduction would not be the preferred $\mathrm{O}_{2}$ production method; carbothermal reduction or other non-mineral-specific processes must be pursued.

\subsection{Beyond the Moon: Future Human Exploration Options}

From the 1950s through the 1980s ambitious robotic and human missions were planned for outer space - targeting places from Mercury to the outermost reaches of the solar system (Refs. 43 to 47). Although robotic missions continue to be endorsed today, any new human exploration of the solar system still awaits promotion.. While investments in robotic missions have continued, human exploration of the solar system has awaited new invigorating steps. Beyond the Moon, Mars represents an obvious destination for human exploration, and also a rich destination for use of in-situ resources. Mars resource utilization is incorporated into reference plans for exploration of Mars (Ref. 48). The literature on Mars resource extraction and utilization is sufficiently extensive that it will not be covered in this paper. Future human missions to other destinations such as Mercury and Saturn will also require long-term investments. Currently, Mercury and Saturn have robotic missions returning invaluable data on those planets and their environs. These data have provided insights that will ensure the success of future missions. With its proximity to the Sun, Mercury has extremely high temperatures and requires special high heat flux considerations for long-term human visits or bases. In contrast, temperatures at Saturn and its moons require designs for cryogenic environments. The possibilities for ISRU may allow more effective robotic missions and human visits to these planetary targets.

\subsection{Mercury}

Mercury is the closest planet to the Sun; ranging from a perihelion of $46,000,000 \mathrm{~km}$ to an aphelion of nearly $70,000,000 \mathrm{~km}$. The high temperature, high heat flux environment at Mercury and the tenuous surface emanations of several major chemical species (sodium, etc.) will likely pose challenges to long term human visits. Permanently shadowed craters offer a valuable niche for longer-term human visits and planetary bases. Such craters offer cryogenic temperatures while the Sun-facing surface is at a temperature of 590 to $725 \mathrm{~K}$. The north Polar Regions of Mercury have been identified as a likely location for such permanently shadowed craters (Refs. 49 to 51). Water ice is also likely to be in these craters, further aiding and assisting any human exploration(s). Short exploratory missions can be accomplished with hopping ascentdescent vehicles from the base at the shadowed crater.

Figure 10 shows locations of the shadowed craters (Ref. 50). Figure 11 depicts the temperatures that would exist in and near the craters (Ref. 51). The crater could accommodate a small base or at least an initial landing site. The lander's temperature could stay within the nominal operating temperatures of traditional spacecraft. The temperature distribution in the crater 


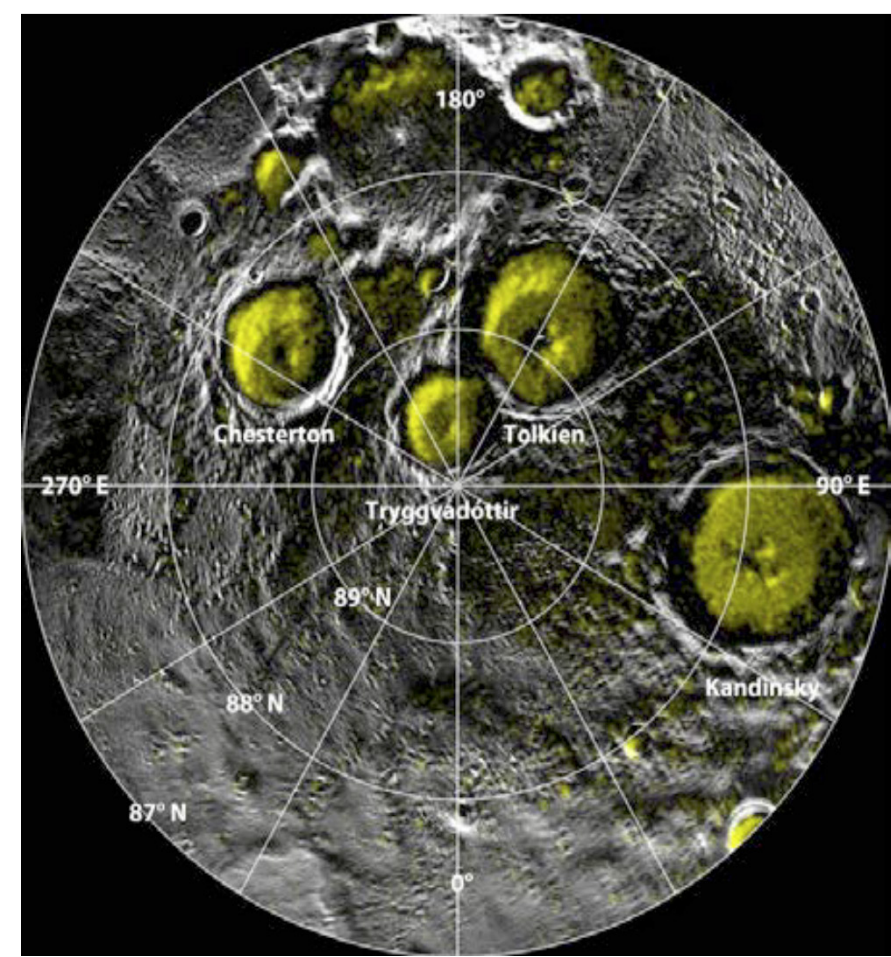

Figure 10.-Permanently shadowed craters in Mercury's north polar region (from Ref. 50).

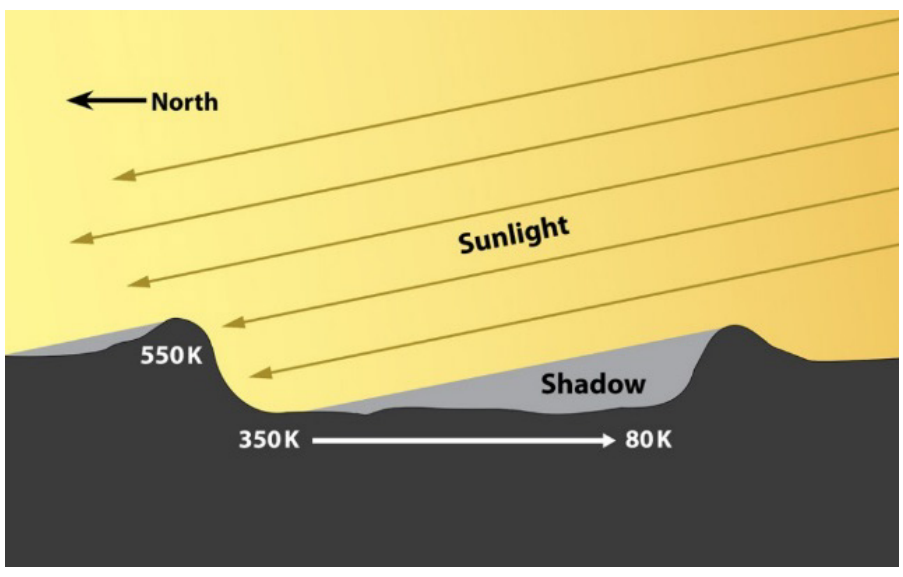

Figure 11.- Temperature ranges outside and inside permanently shadowed craters (from Ref. 51).

would allow construction of the base at the warmer side of the crater and then the frozen volatiles would be extracted with cryogenic mining machines.

\subsection{Mercury Missions}

A human round trip mission to Mercury was assessed. The mission $\Delta \mathrm{V}$ values for the round trip Mercury missions were derived from the literature (Refs. 52 to 55). The highest $\Delta \mathrm{V}$ case was selected from this data: an Earth departure $\Delta V$ of $5.2 \mathrm{~km} / \mathrm{s}$, a Mercury arrival $\Delta \mathrm{V}$ of $10.9 \mathrm{~km} / \mathrm{s}$ and a Mercury departure $\Delta \mathrm{V}$

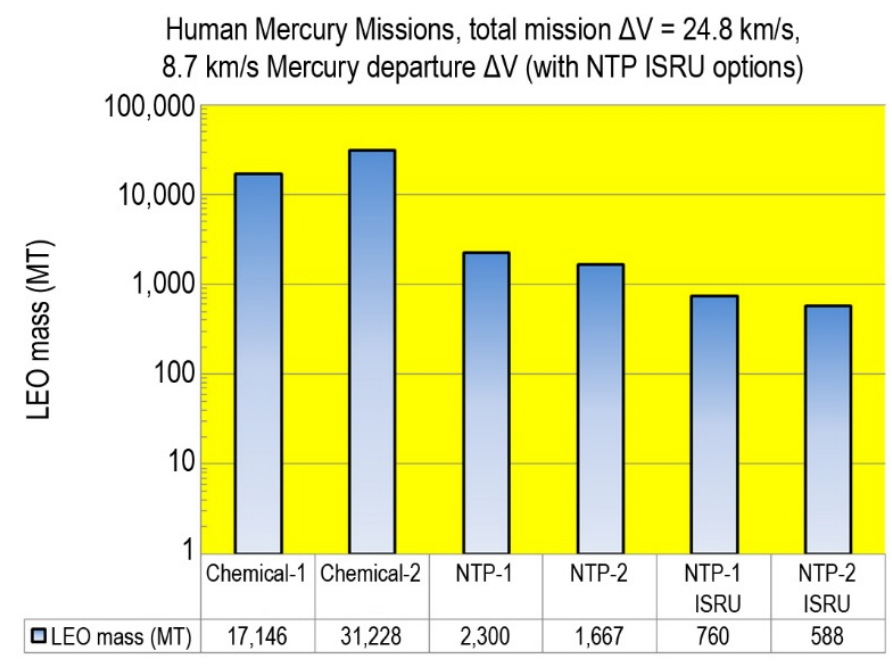

Figure 12.-LEO masses of human round trip missions to Mercury.

of $8.7 \mathrm{~km} / \mathrm{s}$ (Ref. 52). At Earth a capsule enters the atmosphere to return the crew directly to Earth. The capsule's mass is $4,350 \mathrm{~kg}$; the round trip time is 585 days with a 40 -day stay time at Mercury (Ref. 52). In this case, the vehicle does not land on Mercury. The LEO masses of both chemical propulsion and nuclear thermal propulsion (NTP) vehicles were estimated. Figure 12 compares the LEO masses for two types of chemical propulsion systems and two NTP systems. The interplanetary chemical propulsion systems used tankage dry mass coefficients of 3 and 5 percent of the total propellant mass in the tankage. In many cases, these dry masses may be deemed to be optimistically low; however, they allow some relative comparison of the chemical propulsion and the nuclear mission cases.

The NTP vehicles dry mass was 15 percent of the propellant mass. In current NTP designs, an $\mathrm{I}_{\mathrm{sp}}$ of $900 \mathrm{~s}$ is nominally used (Refs. 39 and 56). Somewhat lower $I_{\mathrm{sp}}$ values were used for these missions: 800 and $850 \mathrm{~s}$, respectively. These lower $\mathrm{I}_{\mathrm{sp}}$ values were assumed given the high heat flux environment of Mercury and the degraded $I_{s p}$ values would reflect the added propellant used for propellant cooling and/or refrigeration. The chemical propulsion systems required between 17,146 and 31,228 MT to accomplish the mission. The NTP vehicles required approximately an order of magnitude less mass in LEO: 1,667 to 2,300 MT. Based on our prior analysis, the stage and lander mass was estimated with a mass scaling Equation (19) (Ref. 57).

$$
\mathrm{M}_{\text {dry,stage }}(\mathrm{kg})=\mathrm{M}_{\text {dry }, \text { coefficient }} \cdot \mathrm{M}_{\mathrm{p}}(\mathrm{kg})
$$

A Mercury landing vehicle mass was also estimated; the oneway $\Delta \mathrm{V}$ for the lander was $3.5 \mathrm{~km} / \mathrm{s}$ (Ref. 58). The ascent $\Delta \mathrm{V}$ was also $3.5 \mathrm{~km} / \mathrm{s}$. These $\Delta \mathrm{V}$ values accommodate approximately 19 percent for gravity losses for each maneuver; this 
gravity loss $\Delta \mathrm{V}$ is added to the orbital velocity for a $100 \mathrm{~km}$ orbit which is $2.945 \mathrm{~km} / \mathrm{s}$. The lander $\mathrm{I}_{\mathrm{sp}}$ was $480 \mathrm{~s}$. The higher $\mathrm{I}_{\mathrm{sp}}$ was chosen for the lander as the engine used a higher engine expansion ratio that the interplanetary transfer vehicle (Ref. 57). The smaller engine size would allow a higher expansion ratio, given the typical volume constraints for space vehicles. The dry mass coefficient was 20 percent of the total propellant load. While the Mercury missions will likely require more aggressive thermal control (propellant shielding, cooling, etc.), that thermal control system mass is accommodated in the payload mass of the vehicle. The payload delivered to the surface was 10 MT. Figure 13 compares the mass in LEO of a oneway lander and a round trip lander. The masses were $140 \mathrm{MT}$ for the round trip lander and 27 MT for the one-way lander. Thus, using ISRU on the surface of Mercury to replenish the lander's propellant would allow a savings of 113 MT on this mission. Additional analyses are needed to investigate the mass reductions for the interplanetary transfer vehicle to carry the lander to Mercury. Another option would be to carry five landers to Mercury rather than carry simply one lander; many more permanently shadowed craters could then be visited on one mission. The interplanetary vehicle carrying the five landers could be sent on a lower energy trajectory than the human flights, thus saving additional mass launched into LEO in the overall Mercury architecture.

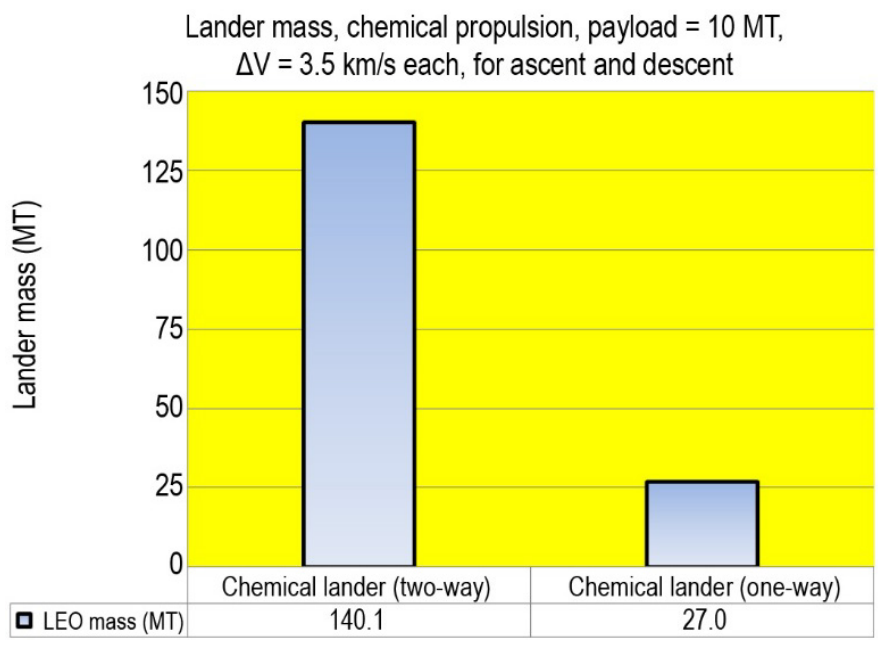

Figure 13.-_LEO masses of landers for missions to Mercury.

TABLE VI.-SPACE VEHICLE DRY MASS COEFFICIENT AND ROCKET ENGINE SPECIFIC IMPULSE $\left(\mathrm{I}_{\mathrm{sp}}\right)$

\begin{tabular}{|l|c|c|}
\hline \multicolumn{1}{|c|}{ Technology } & $\begin{array}{l}\mathrm{I}_{\mathrm{sp}}, \\
\mathrm{sec}\end{array}$ & $\begin{array}{c}\mathrm{M}_{\text {dry,coefficient }}, \\
\mathrm{kg} / \mathrm{kg} \mathrm{M,p}\end{array}$ \\
\hline Chemical-1 & 450 & 0.03 \\
\hline Chemical-2 & 450 & 0.05 \\
\hline Chemical lander & 450 & 0.20 \\
\hline NTP-1 & 800 & 0.15 \\
\hline NTP-2 & 850 & 0.15 \\
\hline
\end{tabular}

Using Mercury resources to augment the human missions was investigated. An ISRU system's effect on reducing the LEO mass (see Table VI for details) was analyzed. For the NTP-1 and -2 systems, cases were computed where the Mercury departure $\Delta \mathrm{V}$ propellant was supplied at Mercury. The Mercury departure stage is brought from Earth with no propellant. Hydrogen would be produced from the water at the northern polar craters, and transported to orbit. For the NTP-1 case, $94 \mathrm{MT}$ of $\mathrm{H}_{2}$ would be transported to orbit. With NTP-2, the propellant mass required in Mercury orbit is $82 \mathrm{MT}$. With the in-situ $\mathrm{H}_{2}$ production, the LEO mass of the NTP-1 case is reduced from 2300 to $760 \mathrm{MT}$, as shown in Figure 12. Similar large LEO mass reductions are enabled for the NTP-2 system; using ISRU, the $1667 \mathrm{MT}$ LEO mass is reduced to $588 \mathrm{MT}$.

Additional summary data on mission design is summarized in a review. Figure 14 provides a map of the one-way $\Delta \mathrm{V}$ and trip time for a wide range of planetary targets (Ref. 55). Fast missions to Jupiter and Mercury are possible with $\Delta \mathrm{V}$ values of 80 to $100 \mathrm{~km} / \mathrm{s}$. Nuclear propulsion systems may someday allow such ambitious missions and if augmented by ISRU, such mission will be within our technological reach.

\subsection{Venus}

The next planet out from the Sun, Venus, is one of the most hostile surface environments in the solar system, with a surface temperature of $450{ }^{\circ} \mathrm{C}$ at an atmospheric pressure of 92 bars. Nevertheless, Venus, as a rocky planet with a thick atmosphere, is the planet in the solar system that is in many ways most similar to the Earth, and hence scientific study of Venus is of significant interest. The atmosphere, consisting primarily of $\mathrm{CO}_{2}$ and $\mathrm{N}_{2}$, with clouds of sulfuric acid, represents a resource that may be of interest in long-term human settlement.

As with Earth, the temperature in the atmosphere decreases due to adiabatic lapse as the altitude increases, and at an altitude of about $56 \mathrm{~km}$ above the surface, the temperature reaches Earthlike values of about $20{ }^{\circ} \mathrm{C}$, at a pressure of about half a bar. If human habitats were to be emplaced at Venus, this altitude would be an Earthlike location (Ref. 59).

Terraforming, the process of altering a planetary environment to make it hospitable to life, has been proposed for both Venus and Mars (Ref. 60). Terraforming Venus is a process which would require long periods of time and large expenditures of energy, but which may not be beyond the reach of future engineering capabilities (Ref. 61).

\subsection{Jupiter and Its Moons}

Jupiter, the largest planet in the solar system, is a challenging target for exploration. Because of the high gravity and deep gravitational well, Jupiter itself is probably beyond the reach of 


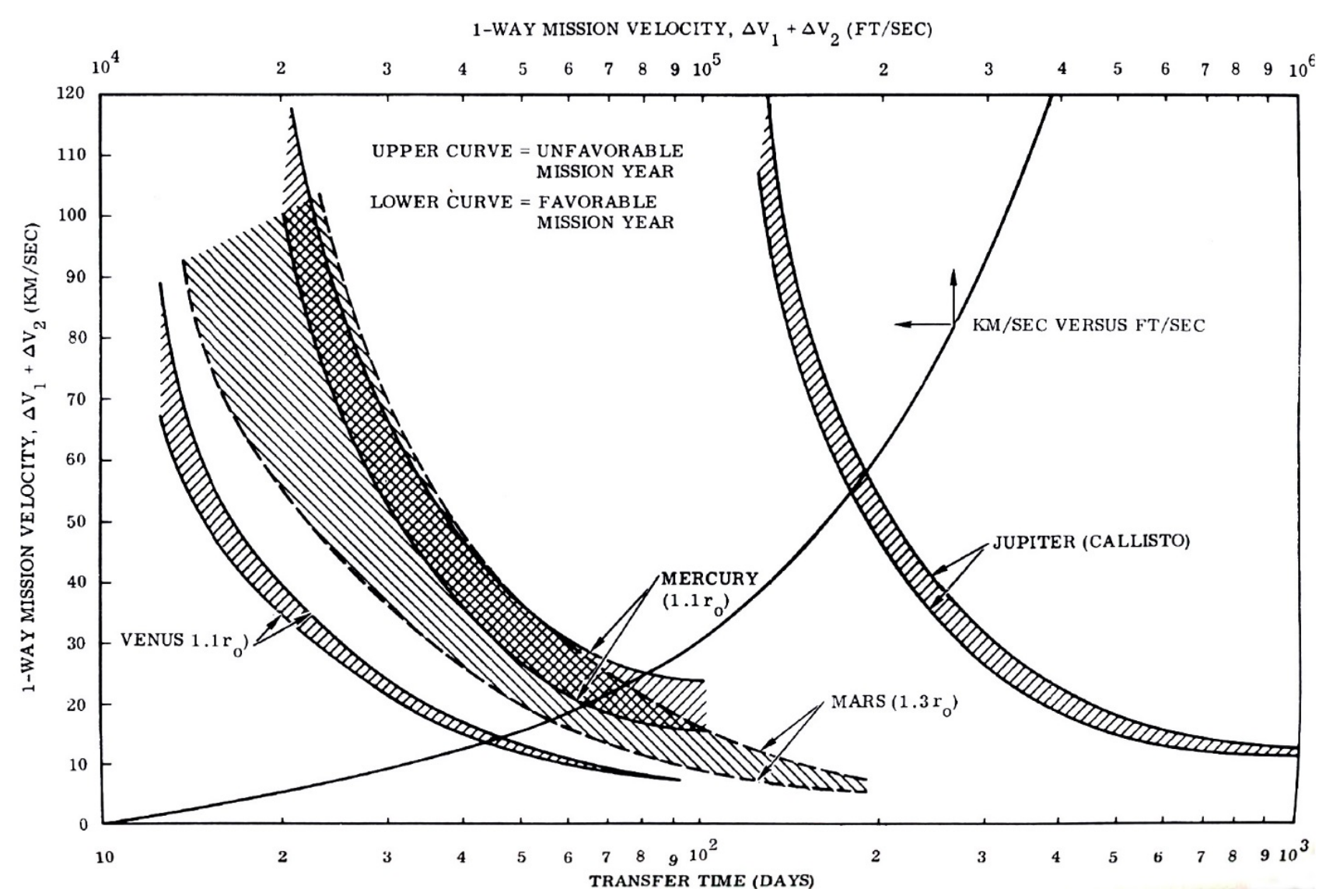

Figure 14.-One-way interplanetary mission $\Delta \mathrm{V}$ versus trip time for various targets (from Ref. 54 , used with permission ${ }^{1}$ ).

human exploration, but the extensive system of Jovian moons, including the four large Galilean moons and a number of smaller moons. The innermost moon, Io, has a volcanic, sulfurrich surface; Europa shows an icy surface, while Callisto and Ganymede show evidence of regolith on the surface covering ice. Europa and Ganymede, and very likely also Callisto, also shows evidence of a subsurface ocean. Of these, only Callisto lies outside the Jovian radiation belts, and hence is a reasonable target for human exploration (Ref. 62).

Beyond the large Galilean moons, the smaller moons of Jupiter are asteroid-like bodies, which very likely are partly or mostly ice in composition. The Trojan asteroids, leading and trailing Jupiter's orbit around the Sun, also represent sources of ice. Thus, the moons of Jupiter may well be a source of volatile elements, primarily water, which may represent useful resources for production of fuel and life-support consumables.

${ }^{1}$ This figure was originally presented at the American Astronautical Society (AAS) $16^{\text {th }}$ Annual Meeting, Anaheim, CA, and was originally published in the AAS publication "Space Shuttles and Interplanetary

\subsection{Saturn and Its Moons}

Saturn is one of the outer planets. Its orbit has a perihelion of $1,352,600,000 \mathrm{~km}$ and an aphelion of 1,514,500,000 km. The Cassini spacecraft has conducted an extensive series of flybys of the Saturnian moons. During these flybys, cameras and instruments capture and data on the moons' composition, atmosphere and cloud cover (on the moon Titan), volcanoes, plumes, rotation, and gravity.

Titan is the largest moon of Saturn. It is the second largest moon in the solar system, the only moon with an atmosphere, and the only body in the solar system (other than Earth) that shows bodies of liquid on its surface. It is thus one of the most scientifically interesting targets for exploration in the solar system. Its intriguing nature includes a $\mathrm{N}_{2}$ and $\mathrm{CH}_{4}$ atmosphere and a subsurface ocean, as shown in Figure 15 (Ref. 63). Recent

Flight,” ed. L. Larmore and R.L. Gervais, Vol. 28, Advances in Astronautical Sciences, 1970, p. 364 (Copyright (C) 1970 by American Astronautical Society Publications Office, Web Site http://www.univelt.com) 


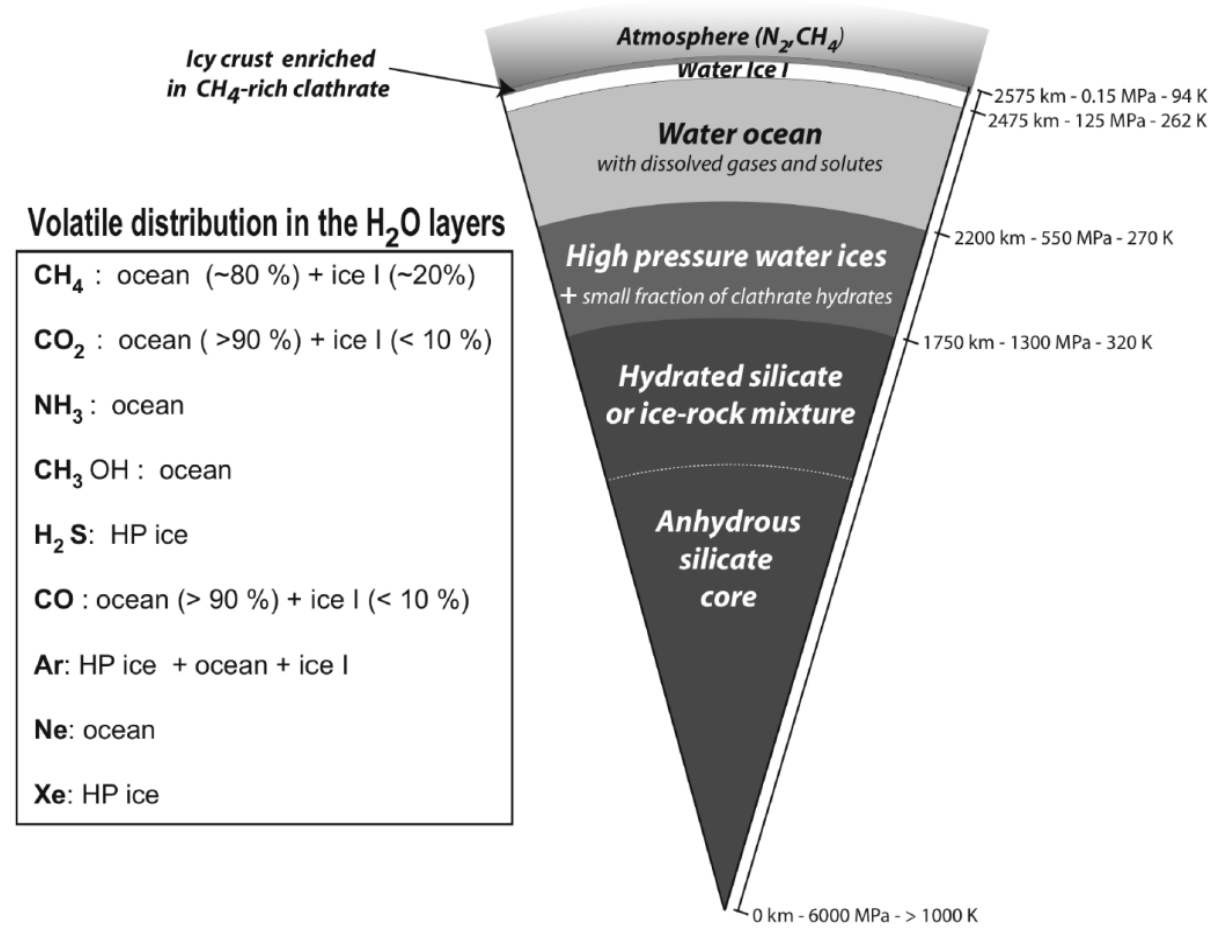

Figure 15.-Possible present day cross-section of Titan (from Ref. 63, Tobie, G., Lunine, J.I., Monteux, J., Mousis, O., and Nimmo, F., "The Origin and Evolution of Titan," in Titan: Interior, Surface, Atmosphere and Space Environment, Müller-Wodarg, I., Griffith, C.A., Lellouch E., and Cravens, T.E., eds., Cambridge Univ. Press, Cambridge, U.K., 2012, pp. 24-50.) Used with permission.

flybys of the Cassini spacecraft have shown direct visual evidence of the northern lakes which are likely composed of $\mathrm{CH}_{4}$. Based on measurements and theories of the evolution of Titan, a large ocean of water and ammonia may exist below the icy surface. Large lakes in the northern Polar Regions have been seen on Titan's surface, and they are likely composed of $\mathrm{CH}_{4}$. Figure 15 shows the possible nature of Titan's interior, surface, and atmosphere. While $\mathrm{CH}_{4}$ can be used as an effective rocket propellant, its $\mathrm{N}_{2}$ could be used in cold gas propulsion or electric propulsion (resistojet, arcjet or magneto-plasma-dynamic thrusters).

\subsection{Atmospheric Mining in the Outer Solar System}

Atmospheric mining in the outer solar system (AMOSS) can be a powerful ISRU tool in extracting fuels from the outer planets and allow fast human and robotic exploration of the solar system. Preliminary designs of aerospacecraft with gas core rocket nuclear engines for mining the outer planets were developed (Ref. 39 and 56). Helium-3 ( ${ }^{3} \mathrm{He}$ ), a possible fuel for advanced nuclear fusion reactor cycles based on the $\mathrm{D}^{3} \mathrm{He}$ reaction, would be extracted from the atmosphere and stored for final delivery to orbital assets.
The outer planets Uranus and Neptune are the most reasonable targets for such atmospheric extraction of ${ }^{3} \mathrm{He}$, since their atmospheres, although primarily $\mathrm{H}_{2}$, contain significant amounts of $\mathrm{He}$, and the gravitational potential is much less steep than that of Jupiter or Saturn.

Analyses showed that gas core nuclear rocket (GCNR) engines can reduce the mass of such aerospacecraft mining vehicles very significantly: from 72 to 80 percent reduction over NTP solid core powered aerospacecraft mining vehicles. While this mass reduction is important in reducing the mass of the overall mining system, the complexity of a fissioning plasma gas core rocket is much higher than the more traditional solid-core NTP engines. Additional analyses were conducted to calculate the capture rates of ${ }^{3} \mathrm{He}, \mathrm{H}_{2}$, and ${ }^{4} \mathrm{He}$ during the mining process. Very large masses of $\mathrm{H}_{2}$ and ${ }^{4} \mathrm{He}$ are produced every day during the often-lengthy process (multi-day) of ${ }^{3} \mathrm{He}$ capture and gas separation.

Figure 16 shows the mass of $\mathrm{H}_{2}$ needed for the gas core rocket and the potentially excess $\mathrm{H}_{2}$ captured every day (Ref. 56). Typically, these very large additional fuel masses can dwarf the requirements needed for $\mathrm{H}_{2}$ captured for ascent to orbit. Thus, the potential for fueling small and large fleets of additional exploration and exploitation vehicles exists. Aerial vehicle 


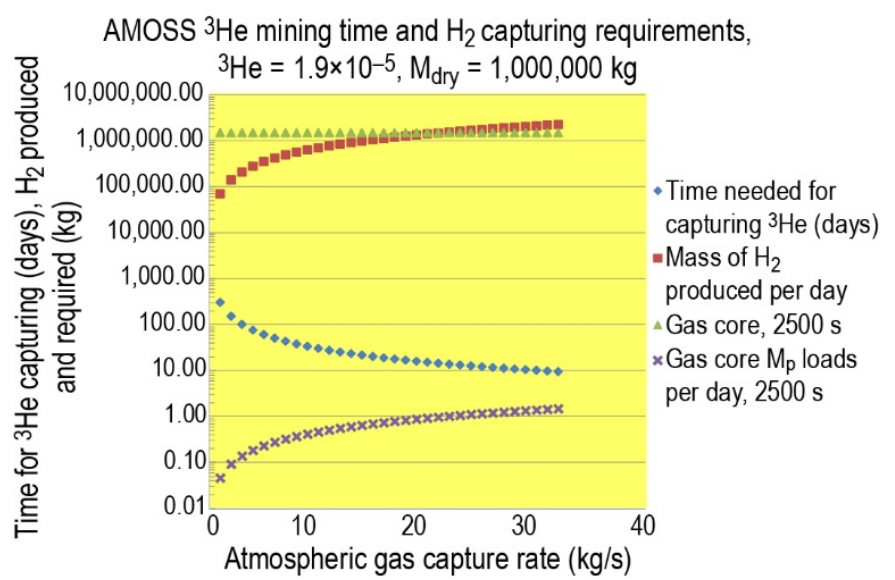

Figure 16.-Helium-3 mining time and $\mathrm{H}_{2}$ capture (mass per day) versus atmospheric gas capture rate for Neptune AMOSS.

designs can take on many configurations. Additional aerospacecraft or other uninhabited aerial vehicles, or balloons, rockets, etc., could fly through the outer planet atmospheres, for global weather observations, localized storm or other disturbance investigations, wind speed measurements, polar observations, etc. Deep-diving aircraft (built with the strength to withstand many atmospheres of pressure) powered by the excess $\mathrm{H}_{2}$ or ${ }^{4} \mathrm{He}$ may be designed to probe the higher density regions of the gas giants.

Based on these past analyses, there will likely be several possible future avenues for effective use the gases of the outer planets for exciting and scientifically important atmospheric exploration missions. The analyses focused on Uranus and Neptune, as these planets offer vast reservoirs of fuels that are more readily accessible than those from Jupiter and Saturn (as these latter planets require lower energies needed to attain orbit and present less danger from powerful atmospheric lightning) and, with the advent of nuclear fusion propulsion, may offer us the best option for fast interplanetary travel and the first practical interstellar flight.

\subsection{Conclusions}

As amply demonstrated in this retrospective survey, "living off the land" imposes constraints for utilization of power, propellants, and other expendables. The normal rigors (mass, space limitations and environmental challenges) imposed by space travel are magnified by a resource-limited situation. On the other hand, enhanced energy efficiency and minimal launch mass will simplify missions (and increase successful outcomes) by resultant limitations to planned activities. Thus the technical hurdles and challenges alluded to above will stimulate development of technology solutions for space exploration that can be spun off to solve terrestrial problems for defense, and dual-use applications such as and commercial transportation, power generation, and efficient resource utilization. Another important aspect of the GRC effort that should certainly not be overlooked is the variety of individual collaborations fostered, organizational partnerships formed, and mentored students educated and into the aerospace community as a result of the technical work.

In-flight utilization of waste and trash to produce essential materials such as water, fuel(s), and $\mathrm{O}_{2}$ is an anthropogenic-waste application of an ISRU approach for sustainability. For prudent and efficient utilization of terrestrial raw materials and energy for transportation fuel production, re-use or recovery of hydrocarbons and waste is becoming increasingly critical in overall mission designs. In an effort to provide fresh water through desalination in a clean, economical, and environmentally friendly way, a solar powered water desalination facility located in Yuma, Arizona, was considered. Such a facility powered by solar concentrators would be able to fund itself during operation, assuming public financing covered costs for the plant; unless the capital equipment costs of solar concentrators decrease, the facility would not be able to recoup the initial startup cost. Nevertheless, the system would still save money in the long run.

Production of $\mathrm{O}_{2}$ from local materials can fuel a transportation system that supports the lunar base, as well as serving as a possible product for use in propulsion systems either commercially or to support exploration of other locations. Replacement $\mathrm{O}_{2}$ is also a necessary product for life support, since even closed-ecological life support systems will not have perfect efficiency of recycling. Because the Moon's axis is angled $1.5^{\circ}$ from the ecliptic, the South Pole is almost constantly bathed in sunlight; during lunar summer, the entire South Pole is visible, and during lunar winter, the Shackleton crater and other small southern regions are illuminated by the Sun for more than 70 percent of the time. Such areas would be an ideal place for a constantly operating solar concentrator that could generate approximately twice the amount of $\mathrm{O}_{2}$ than an ISRU system anywhere else on the Moon.

Fast missions to Jupiter and Mercury are possible with $\Delta \mathrm{V}$ values of 80 to $100 \mathrm{~km} / \mathrm{s}$. Nuclear propulsion systems may someday allow such ambitious missions and if augmented by ISRU, such mission will be within our technological reach. With its proximity to the Sun, Mercury has extremely high temperatures and requires special high heat flux considerations for long-term human visits or bases. There will likely be several possible future avenues for effective use the gases of the outer planets for exciting and scientifically important atmospheric exploration missions. The analyses focused on Uranus and Neptune, as these planets offer vast reservoirs of fuels that are relatively readily accessible; with the advent of nuclear fusion propulsion, these most distant gas giants may offer us the best option for fast interplanetary travel and the first practical interstellar flight. 


\section{References}

1. Huntress, W., Stetson, D., Farquhar, R., Clark, B., O’Neil, W., Bourke, R., and Foing, B., "The Next Steps in Exploring Deep Space - A Cosmic Study by the IAA," Acta Astronautica, Vol. 58, No. 6-7, pp. 304-377, 2006.

2. Lewis, J., Matthews, M.S., and Guerrieri, M.L. (eds.), Resources of Near-Earth Space, The University of Arizona Press, Tuscon, AZ, pp. 3-17, 1993.

3. Hepp, A.F., Linne, D.L., Landis, G.A., Wadel, M.F., and Colvin, J.E., "Production and Use of Metals and Oxygen for Lunar Propulsion," J. Propul. Power, Vol. 10, No. 6, pp. 834-840, 1994.

4. Colozza, A. J., Heller, R. S., Wong, W. A., and Hepp, A. F., "Solar Energy Systems for Lunar Oxygen Generation," NASA/TM-2010-216219, AIAA-2010-1166, Apr. 2010.

5. Gordon, P.E., Colozza, A.J., Hepp, A.F., Heller, R.S., Gustafson, R., Stern, T. and Takashi, N., "Thermal Energy for Lunar In-situ Resource Utilization: Technical Challenges and Technology Opportunities," NASA/TM-2011217114, AIAA-2011-704, Oct. 2011.

6. Landis, G.A. and Linne, D.L., "Acetylene Fuel from Atmospheric $\mathrm{CO}_{2}$ on Mars," J. Spacecraft Rockets, Vol. 29, No. 2, pp. 294-296, 1992.

7. Hepp, A.F., Landis, G.A., and Kubiak, C.P., "A Chemical Approach to Carbon Dioxide Utilization on Mars," in Resources of Near-Earth Space, J. Lewis, M.S. Matthews, and M.L. Guerrieri (eds.), University of Arizona Press, Tucson, AZ, pp. 799-818, 1993.

8. Landis, G.A. and Linne, D.L., "Mars Rocket Vehicle Using In-Situ Propellants," J. Spacecraft Rockets, Vol. 38, No. 5, pp. 730-735, 2001.

9. Colozza, A., Landis, G. and Lyons, V., "Overview of Innovative Aircraft Power and Propulsion Systems and Their Applications for Planetary Propulsion," NASA/TM2003-212459, Jul. 2003.

10. Heller, R.S., Landis, G.A., Hepp, A.F. and Colozza, A.J., "Heated-Atmosphere Airship for the Titan Environment: Thermal Analysis," NASA/TM-2012-217639, Jul. 2012.

11. Al-Salem, S.M., Lettieri, P., and Baeyens, J., "The Valorization of Plastic Solid Waste (PSW) by Primary to Quaternary Routes: From Re-Use to Energy and Chemicals," Prog. Energy Combust. Sci., Vol. 36, No. 1, pp. 103-129, 2010.

12. Palaszewski, B.A., Hepp, A.F., Kulis, M.J., and Jaworske, D.A., "Aerospace Fuels from Nonpetroleum Raw Materials," NASA/TM-2013-216492, AIAA-2013-591, Feb. 2013.

13. Hepp, A.F., Kulis, M.J., De La Ree, A.B., Zubrin, R., Berggren, M., Hensel, J.D., and Kimble, M.C., "Green Aerospace Fuels from Nonpetroleum Sources," NASA/TM2011-217027, AIAA-2011-702, Jun. 2011.
14. Kankam, M.D., Lyons, V.J., Hoberecht, M.A., Tacina, R.R., and Hepp, A.F., "Recent GRC Aerospace Technologies Applicable to Terrestrial Energy Systems," J. Propul. Power, Vol. 18, No. 2, pp. 481-488, 2002.

15. Peña, M.A., Gómez, J.P., and Fierro, J.L.G., "New Catalytic Routes for Syngas and Hydrogen Production," Appl. Catal. A-Gen., Vol. 144, No. 1-2, pp. 7-57, 1996.

16. Kopyscinski, J., Schildhauer, T.J., Biollaz, S.M.A., "Production of Synthetic Natural Gas (SNG) from Coal and Dry Biomass - A Technology Review from 1950 to 2009," Fuel, Vol. 89, No. 8, pp. 1763-1783, 2010.

17. Brooks, K.P., Hu, J., Zhu, H., and Kee, R.J., "Methanation of Carbon Dioxide by Hydrogen Reduction Using the Sabatier Process in Microchannel Reactors," Chem. Eng. Sci. Vol. 62, No. 4, pp. 1161-1170, 2007.

18. Liu, Z., Chu, B., Zhai, X., Jin, Y., and Cheng, Y., "Total Methanation of Syngas to Synthetic Natural Gas over Ni Catalyst in a Micro-Channel Reactor," Fuel, Vol. 95, No. 1, pp. 599-605, 2012.

19. Khodakov, A.Y., Chu, W., and Fongarland, P., “Advances in the Development of Novel Fischer-Tropsch Catalysts for Synthesis of Long-Chain Hydrocarbons and Clean Fuels," Chem. Rev., Vol. 107, No. 5, pp. 1692-1744, 2007.

20. Hepp, A.F., Kulis, M.J., Psarras, P.C., Ball, D.W., Timko, M.T., Wong, H.-W., Peck, J., and Chianelli, R.R., "Novel Catalysts and Processing Technologies for Production of Aerospace Fuels from Non-Petroleum Raw Materials," NASA/TM-2014-218326, AIAA-2014-0340, Jul. 2014.

21. Jaworske, D.A., Colozza, A., and Sechkar, E.A., "Design for On-Sun Evaluation of Evaporator Receivers," $9^{\text {th }}$ International Energy Conversion Engineering Conference, San Diego, CA, AIAA-2011-5719, Aug. 2011.

22. Colozza, A.J., Macosko, R., Castle, C., Sacksteder, K., Suzuki, N.H. and Mulherin J., "Casegrain Solar Concentrator System for ISRU Material Processing," 50th AIAA Aerospace Sciences Meeting, AIAA-2012-0637, Jan. 2012.

23. Gustafson, R.J., White, B.C., and Fidler, M.J., "Demonstrating Lunar Oxygen Production with the Carbothermal Regolith Reduction Process," 47 $7^{\text {th }}$ Aerospace Sciences Meeting, Orlando, FL, AIAA-2009-663, 2009.

24. Nakamura, T., and Senior, C.L., "Solar Thermal Power For Lunar Materials Processing," J. Aerospace Eng., Vol. 21, No. 2, pp. 91-101, 2008.

25. Hoffman, S.J. and Kaplan, D.I. eds., "Human Exploration of Mars: The Reference Mission of the NASA Mars Exploration Study Team," NASA/SP_-1997-6107, pp. 3-102, Jul. 1997.

26. Donnelly, J., "Russia Top Offender in Gas-Flare Emmissions," The Boston Globe, 21 Jun. 2007.

27. Udom, I., Goswami, D.Y., Ram, M.K., Stefanakos, E.K., Hepp, A.F., Kulis, M.J., McNatt, J.S., Jaworske, D.A., and 
Jones, C.A., "Enhanced $\mathrm{TiO}_{2}$ Photocatalytic Processing of Organic Wastes for Green Space Exploration," NASA/TM-2013-217844, AIAA-2013-588, Feb. 2013.

28. Kim, K.-H. and Ihm, S.-K., "Heterogeneous Catalytic Wet Air Oxidation of Refractory Organic Pollutants in Industrial Wastewaters: A Review," J. Hazard. Mater., Vol. 186, No. 1, pp. 16-34, 2011.

29. Jeftic, L., Sheavly, S., and Adler, E., "Marine Litter: A Global Challenge," United Nations Environment Programme, Apr. 2009.

30. Lappas, A.A., Samolada, M.C., Iatridis, D.K., Voutetakis, S.S., and Vasalos, I.A., "Biomass Pyrolysis in a Circulating Fluid Bed Reactor for the Production of Fuels and Chemicals," Fuel, Vol. 81, No. 16, pp. 2087-2095, 2002.

31. Ducharme, C., "Technical and Economic Analysis of Plasma-Assisted Waste-to-Energy Processes," M.S. Dissertation, Department of Earth and Environmental Engineering, Columbia University, NY, 2010.

32. http://www.saltonsea.ca.gov/thesea.htm, Jul. 2009.

33. Atmosphere-Ocean Model, "Insolation at Specified Location," NASA, http://aom.giss.nasa.gov/srlocat.html, Jul. 2009.

34. Seawater Desalination in California, "Background," California Coastal Commission, http://www.coastal.ca.gov/desalrpt/dchap1.html, Jul. 2009.

35. Landis, G.A., "Materials Refining for Solar Array Production on the Moon," NASA/TM-2005-214014, Jun. 2005.

36. Benaroya, H., Turning Dust into Gold: Building a Future on the Moon and Mars, Springer/Praxis, 2010.

37. Landis, G.A., "Calcium Reduction as a Process for Oxygen Production from Lunar Regolith," AIAA-2011-701, 49th AIAA Aerospace Sciences Conference, Orlando FL, Jan. 4-7, 2011.

38. Landis, G.A., "Materials Refining on the Moon," Acta Astronautica, Vol. 60, No. 10-11, pp. 906-915, 2007.

39. Palaszewski, B., "Atmospheric Mining in the Outer Solar System: Resource Capturing, Storage, and Utilization," AIAA 2012-3742, Jul. 2012.

40. Naval Research Laboratory, "The Clementine Mission," URL: http://www.cmf.nrl.navy.mil/clementine/.

41. Colozza, A.J., and Wong, W.A., "Evaluation of a Stirling Solar Dynamic System For Lunar Oxygen Production," NASA/TM-2006-214360, 2006.

42. Angel, J.R.P., "Buyer's Guide To Telescopes At The Best Sites: Dome A, L2, and Shackleton Rim," Optical, Infrared, and Millimeter Space Telescopes, SPIE Proceedings, Vol. 5487, pp. 1-12, 2004.

43. Ehricke, K.A., "Lunar industrialization and settlement Birth of poly-global civilization," Lunar Bases and Space Activities of the 21st Century Conference, Houston, TX, Lunar and Planetary Institute, pp. 827-855, 1985.
44. Ehricke, K.A., "Harenodynamic cooling - The use of lunar sand as cooling medium," Acta Astronautica, Vol. 11, June No. 6, pp. 319-325, 1984.

45. Ehricke, K.A., "A socio-economic evaluation of the lunar environment and resources: I. Principles and overall system strategy," Acta Astronautica, Vol. 8, Issues Nos. 1112, pp. 1389-1405, Nov.-Dec. 1981.

46. Ehricke, K.A., "Lunar industries and their value for the human environment on Earth." Acta Astronautica, Vol. 1, No. 5, pp. 585-622, 1974.

47. Ehricke, K.A., "Further analyses of the slide lander and of drop delivery systems for improved lunar surface access," Acta Astronautica, Vol. 10, No. 9, pp. 629-650, 1983.

48. Drake, B.G., (ed.), "Human Exploration of Mars: Design Reference Architecture 5.0," NASA/SP-2009-566, Jul. 2009.

49. Lawrence, D.J. et al., "Evidence for Water Ice Near Mercury's North Pole from MESSENGER Neutron Spectrometer Measurements," Science, Vol. 339, No. 6117, pp. 292296, 2013.

50. Chabot, N.L. et al., "Imaging Inside Mercury's Permanently Shadowed Craters - First Images from MESSENGER," Paper 1693, 44th Lunar and Planetary Science Conference, Woodlands, TX, Mar. 18-22, 2013.

51. Paige, D.A. et al., "Thermal Stability of Volatiles in the North Polar Region of Mercury," Science, Vol. 339, No. 6117, pp. 300-303, 2013.

52. Manning, L. "Comparison of Several Trajectory Modes for Manned and Unmanned Missions to Mercury 1980-2000," AIAA 67-28, 1967.

53. Marx, G., "Model study of fuel requirements for fast interplanetary flights using advanced nuclear propulsion systems and refueling at destination," Thesis, Technical University of Berlin (West Germany), in German, May 1967.

54. Ehricke, K. A., "Study of Interplanetary Missions to Mercury through Saturn with Emphasis on Manned Missions to Venus and Mars 1973/82 Involving Capture," Engineering Problems of Manned Interplanetary Exploration, 1963, AIAA 1963-1514, 1963.

55. Ehricke, K., "Perspective and Systems Engineering of Manned Planetary Flight," AAS 70-037, Space Shuttles and Interplanetary Flight, Vol. 28, Advances in Astronautical Sciences, 1970.

56. Palaszewski, B., "Atmospheric Mining in the Outer Solar System: Issues and Challenges for Mining Vehicle Propulsion," AIAA 2011-6041, Aug. 2011.

57. Palaszewski, B., "Metallized Propellants for the Human Exploration of Mars," AIAA Journal of Propulsion and Power, Vol. 8, No. 6, pp. 1192-1199, 1992. 
58. Bensky, M., "Propulsion requirements for soft landing in extraterrestrial environments," Rocketdyne, NAS7-124, NASA CR-55088, Feb. 1963.

59. Landis, G.A., "Colonization of Venus," Conference on Human Space Exploration, in Expanding the Frontiers of Space: AIP Conference Proceedings, Vol. 654, pp. 11931198, 2003.

60. Fogg, M.J., Terraforming: Engineering Planetary Environments, SAE Press, New York, 1995.

61. Landis, G.A., "Terraforming Venus: A Challenging Project for Future Colonization," AIAA Space 2011 Conference \& Exposition, Long Beach, CA, AIAA-2011-7215, Sept. 26$29,2011$.
62. McGuire, M.L., Borowski, S.K., Mason, L.E., and Gilland, J., "High Power MPD Nuclear Electric Propulsion (NEP) for Artificial Gravity HOPE Missions to Callisto," Expanding the Frontiers of Space: AIP Conference Proceedings, Vol. 654, pp. 837-843, 2003.

63. Tobie, G., Lunine, J.I., Monteux, J., Mousis, O., and Nimmo, F., "The Origin and Evolution of Titan," in Titan: Interior, Surface, Atmosphere and Space Environment, Müller-Wodarg, I., Griffith, C.A., Lellouch E., and Cravens, T.E., eds., Cambridge Univ. Press, Cambridge, U.K., pp. 24-50, 2012. 


